Chapter 13

\title{
Interaction of sulphur with bimetallic surfaces: Effects of structural, electronic and chemical properties
}

\author{
José A. Rodriguez and Jan Hrbek \\ Chemistry Department, Brookhaven National Laboratory, Upton, New York \\ 11973, USA
}

\section{Introduction}

Sulphur-containing molecules are common impurities in fuels and oilderived feedstocks [1]. Today these impurities constitute a major problem in our industrial society [2-6]. When fuels are burned, the S-containing impurities react with oxygen, forming sulphur oxides ( $\mathrm{SO}_{\mathrm{x}}$ species). In the atmosphere, the $\mathrm{SO}_{\mathrm{x}}$ compounds undergo further oxidation and interact with water, producing the acid rain that kills vegetation and corrodes buildings and monuments [2]. Furthermore, the $\mathrm{SO}_{2}$ produced in the engine of automobiles poisons the catalysts utilized for the removal of $\mathrm{CO}$ and $\mathrm{NO}$ in exhaust catalytic converters [3]. In general, sulphur poisoning can have a very negative impact on the performance of catalysts currently used for the reforming of hydrocarbons in oil refineries or for the processing of oil-derived feedstocks in the chemical industry [4-6]. Millions of dollars are lost every year in the petroleum and chemical industries as a consequence.

The understanding of the interaction of sulphur with bimetallic surfaces is a critical issue in two important areas of heterogeneous catalysis. On one hand, hydrocarbon reforming catalysts that combine noble and late-transition metals are very sensitive to sulphur poisoning [6,7]. For commercial reasons, there is a clear need to increase the lifetime of this type of catalysts. On the other hand, Mo- and W-based bimetallic catalysts are frequently used for hydrodesulfurization (HDS) processes in oil refineries $[4,5,7,8]$. In order to improve the quality of fuels and oil-derived feedstocks there is a general desire to enhance the activity of HDS catalysts. These facts have motivated many studies investigating the adsorption of sulphur on well-defined bimetallic 
surfaces prepared by the deposition of a metal $(\mathrm{Co}, \mathrm{Ni}, \mathrm{Cu}, \mathrm{Ag}, \mathrm{Au}, \mathrm{Zn}, \mathrm{Al}$ or $\mathrm{Sn}$ ) onto a single-crystal face of another metal (Mo, Ru, Pt, W or Re) [9-29].

Depending on the nature of the metal-sulphur and metal-metal interactions several phenomena can occur when sulphur reacts with a bimetallic surface. For some systems $[13,16,18,21,23]$, one can observe the formation of bimetallic sulphides that exhibit chemical properties very different from those of the pure metals. In another type of systems $[11,14,22,30]$, the interaction between sulphur and one of the metals is repulsive, with sulphur inducing a weakening of the bimetallic bonds and reducing the degree of "mixing" of the metals (i.e. metal $\leftrightarrow$ metal segregation). Also, one can have bimetallic systems in which one of the metals increases or promotes the reactivity of the other toward sulphur $[15-17,19,20,25]$. In some situations, this phenomenon accelerates the poisoning of reforming catalysts $[15,17,25]$, while in anothers, the effect can be beneficial enhancing the activity of catalysts for HDS processes [19,30]. And finally, there can be bimetallic systems in which alloy formation decreases the affinity for sulphur of both metals [26-29]. This is a particularly interesting situation, useful for the design of catalysts with a high tolerance toward sulphur poisoning [2628]. In this chapter we present an overview of all of these different phenomena.

\section{Repulsive interactions between $A u$ and $S$ on transition-metal surfaces}

Catalytic reforming is one of the basic petroleum refining processes, yielding a large variety of liquid fuels $[1,2]$. In reforming, paraffins are reconstructed without changing their carbon number. When an alkane interacts with the surface of a transition-metal catalyst, reactions that lead to the isomerization of the molecule compete with reactions that involve $\mathrm{C}-\mathrm{C}$ bond breaking and produce species with a lower number of carbon atoms [1,2,7]. By adding an inert noble metal ( $\mathrm{Au}, \mathrm{Ag}$ or $\mathrm{Cu}$ ) to a transition metal surface, one can reduce the number of active sites that are present in the system, favoring in this way reactions that require a relatively small ensemble of active sites [31-34]. Thus, catalysts that combine gold and late-transition metals exhibit low activity for $\mathrm{C}-\mathrm{C}$ hydrogenolysis and a high selectivity for the isomerization of hydrocarbons $[31,33,35]$. In these systems, the "wetting" of the surface of the transition metal by gold is a critical factor for the good performance of the catalyst.

A typical Au-thermal desorption spectrum for the pure $\mathrm{Au} / \mathrm{Ru}(0001)$ system, dotted curve in Figure 1, is characterized by features around $1260 \mathrm{~K}$ for desorption of the gold monolayer, with the onset for multilayer desorption appearing at $\sim 1100 \mathrm{~K}[11,36]$. Figure 1 shows $\mathrm{Au}$ - and $\mathrm{S}_{2}$-TDS spectra acquired after dosing $\mathrm{Au}$ to a $\mathrm{Ru}(0001)$ surface pre-covered by $0.27 \mathrm{ML}$ of sulphur [11]. On clean $\operatorname{Ru}(0001)$ this sulfur adlayer is stable up to $1300 \mathrm{~K}$ [37]. For the $\left\{\theta_{\mathrm{Au}}=\right.$ $\left.0.08, \theta_{\mathrm{S}}=0.27\right\}$ and $\left\{\theta_{\mathrm{Au}}=0.29, \theta_{\mathrm{S}}=0.27\right\}$ surfaces, the desorption of $\mathrm{Au}$ occurs 


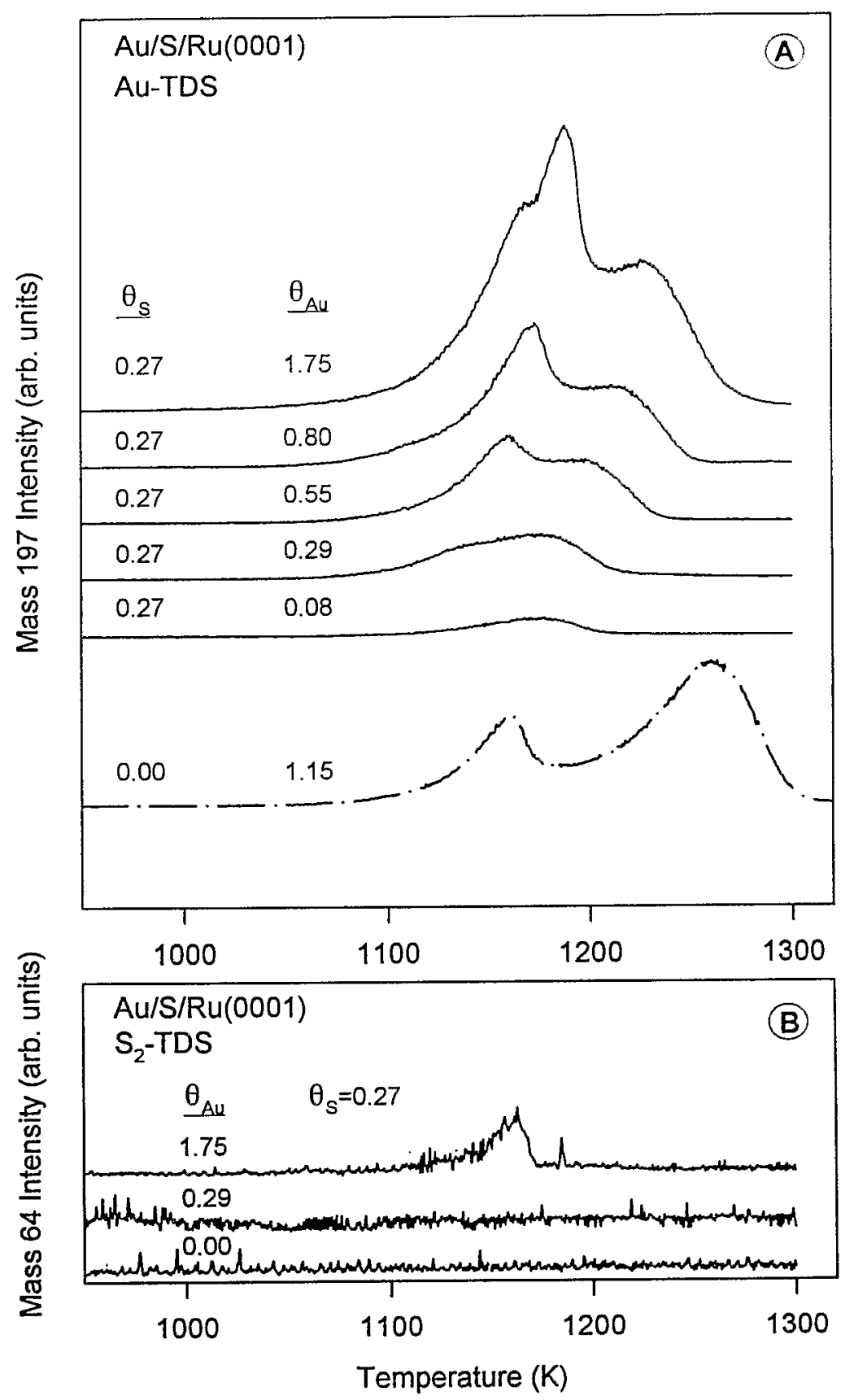

Fig 1 (A) $\mathrm{Au}$-TDS and (B) $\mathrm{S}_{2}$-TDS spectra acquired after dosing Au to a $\mathrm{S}_{0.27} / \mathrm{Ru}(0001)$ surface at $320 \mathrm{~K}$. In (A), the dotted spectrum corresponds to desorption of $1.15 \mathrm{ML}$ of $\mathrm{Au}$ from clean $\mathrm{Ru}(0001)$. Reprinted from ref. [11].

at $\sim 1170 \mathrm{~K}$ (Fig. 1A), without desorption of $\mathrm{S}$ at temperatures below $1300 \mathrm{~K}$. This Au-desorption temperature is $\sim 90 \mathrm{~K}$ smaller than that seen for submonolayer coverages of $\mathrm{Au}$ on clean $\mathrm{Ru}(0001)$ [36]. In the presence of 0.27 ML of $S$, the adsorption energy of Au has decreased by $\sim 6 \mathrm{kcal} / \mathrm{mol}$ [11]. In 
Figure 1A, surfaces with $\mathrm{Au}$ coverage in excess of $0.3 \mathrm{ML}$ show two $\mathrm{Au}$ desorption peaks. The peak at low temperature matches the desorption range for a $\mathrm{Au}$ multilayer [36], and its appearance indicates the presence of threedimensional (3D) islands of $\mathrm{Au}$ on the surface. The peak at high temperature corresponds to $\mathrm{Au}$ atoms in contact with $\mathrm{Ru}$. In the $\left\{\theta_{\mathrm{Au}}=1.75, \theta_{\mathrm{S}}=0.27\right\}$ surface, the presence of $\mathrm{Au}$ forces the desorption of a fraction of the adsorbed sulphur at $\sim 1160 \mathrm{~K}$.

Figure 2 illustrates how Au can affect the desorption pattern of sulfur in a drastic way. The $\mathrm{Au}$ - and $\mathrm{S}_{2}$-TDS spectra were acquired after dosing several coverages of gold to a surface precovered with $0.5 \mathrm{ML}$ of sulphur. For $\mathrm{S}_{0.5} / \mathrm{Ru}(0001)$, the signal for desorption of $\mathrm{S}_{2}$ was close to the noise level of the mass spectrometer and covered a temperature range between 1100 and $1600 \mathrm{~K}$ [11]. The deposition of gold leads to the appearance of a sharp peak for $S_{2}$ desorption from 1150 to $1200 \mathrm{~K}$. No signals for desorption of $S, S_{3}$ or $S_{4}$ were detected. In the presence of gold, $\mathrm{S}$ atoms that were desorbing or diffusing into the bulk of the sample in clean $R u(0001)$ [37] are forced to desorb as $S_{2}$. In the case of $\mathrm{Au} / \mathrm{S}_{0.5} / \mathrm{Ru}(0001)$ systems containing gold coverages in excess of 2.5 ML, XPS measurements indicated that no $S$ was present on the surface after annealing the crystal to $1200 \mathrm{~K}$ [11]. A similar experiment for a $\mathrm{S}_{0.5} / \mathrm{Ru}(0001)$ surface annealed to $1200 \mathrm{~K}$ showed a sulphur coverage of $\sim 0.4 \mathrm{ML}$ [37].

XPS data showed that there was no bonding between $\mathrm{S}$ and $\mathrm{Au}$ atoms coadsorbed on top of $\mathrm{Ru}(0001)$ [11]. In fact, when sulphur was deposited on $\mathrm{Au}$ multilayers supported of $\mathrm{Ru}(0001)$, there was "balling-up" of the metal overlayers as sulphur migrated to the ruthenium underneath. This is not surprising since the Ru-S bond is much stronger than the Au-S bond [37,38]. From the TDS results, it is clear that the interactions between sulphur and gold on the ruthenium surface are either repulsive or both adsorbates compete for bonding with the metal substrate. The trends in Figures 1 and 2 indicate that the amount of $S_{2}$ desorbing at $1170 \mathrm{~K}$ depends strongly on the coverage of gold present on the surface. This behaviour can be explained in the following way [11]. The deposition of $\mathrm{Au}$ on a S-covered $\mathrm{Ru}(0001)$ surface leads to the formation of $3 \mathrm{D}$ islands of $\mathrm{Au}$ which compress the sulphur into small islands of high local coverage. This forces the desorption of a small fraction of the adsorbed $\mathrm{S}$ at $\sim 1170 \mathrm{~K}$. At this point, the $\mathrm{S}$-free $\mathrm{Ru}$ sites can be covered by $\mathrm{S}$ atoms that still remain on the surface or by $\mathrm{Au}$ atoms that diffuse from the $3 \mathrm{D}$ gold islands. The first alternative reduces the local coverage of sulphur and stops $\mathrm{S}_{2}$ desorption, whereas the second option maintains the local coverage of $\mathrm{S}$ high, favoring $S_{2}$ desorption. The second option should be the dominant "reaction channel" when the amount of gold deposited on the surface is very large, leading to complete desorption of sulphur at $\sim 1170 \mathrm{~K}$. 

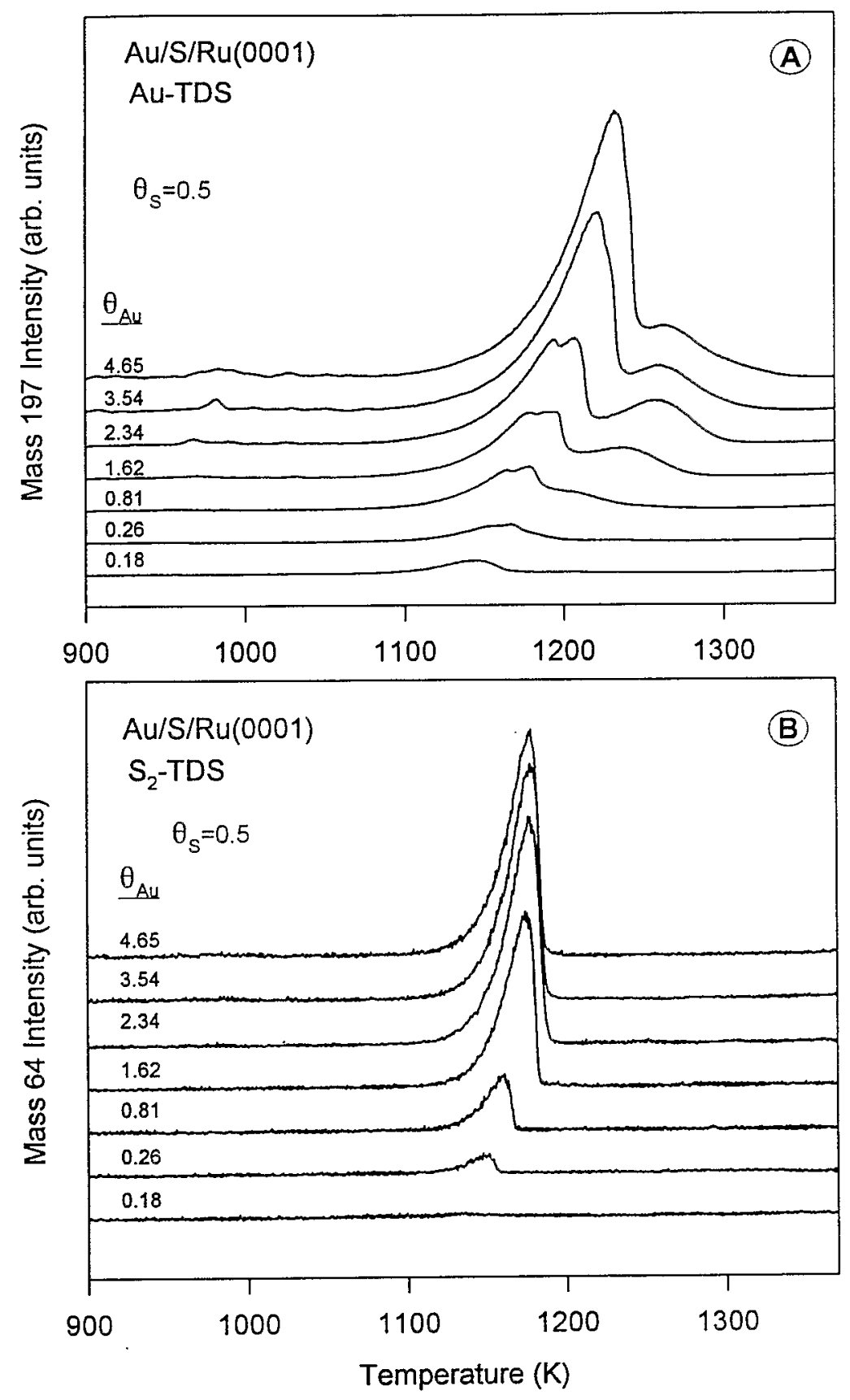

Fig 2 (A) Au-TDS and (B) $S_{2}$-TDS spectra acquired after dosing Au to a $S_{0.5} / R u(0001)$ surface at $320 \mathrm{~K}$. Reprinted from ref. [11].

Images obtained with scanning tunnelling microscopy (STM) indicate that $\mathrm{S}$ and $\mathrm{Au}$ have a tendency to segregate into separate domains or regions when coadsorbed on $\mathrm{Ru}(0001)$ [39]. On atomically flat $\mathrm{Ru}(0001)$, Au grows forming large two dimensional islands that have dendritic shape as shown at the top of Figure 3 [40]. At $300 \mathrm{~K}$, the gold adtoms have a large mobility on the surface and nucleate in these large islands. The bottom of Figure 3 shows an STM 


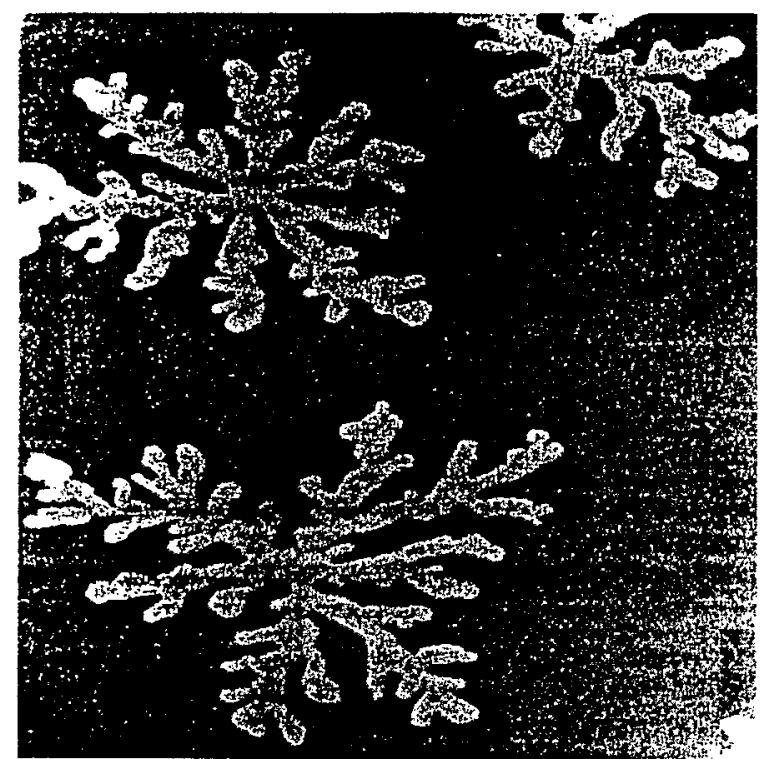

(a)

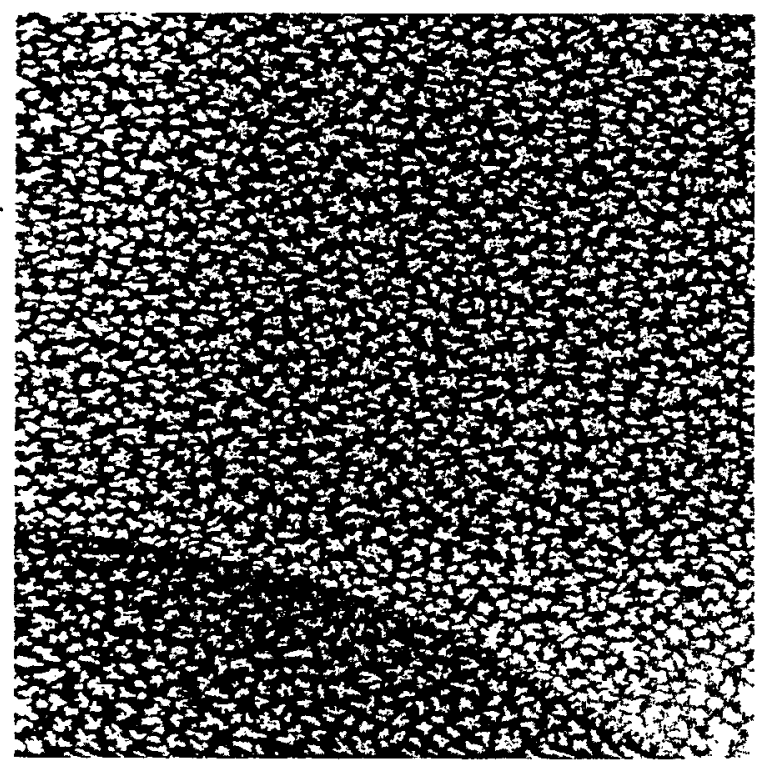

(b)

Fig 3 STM images $\left(1 \mu^{2}\right)$ for the deposition of $\mathrm{Au}$ on clean $\mathrm{Ru}(0001)$, top, and a $\mathrm{S} / \mathrm{Ru}(0001)$ surface with $0.05 \mathrm{ML}$ of $\mathrm{S}$, bottom [39].

image obtained after dosing gold to a $\mathrm{Ru}(0001)$ surface pre-covered with 0.05 $\mathrm{ML}$ of sulphur [39]. Instead of large islands of $\mathrm{Au}$, one sees small aggregates of the admetal. Repulsive interactions between $\mathrm{Au}$ and $\mathrm{S}$ impose severe limitations in the mobility of gold. As the sulfur coverage raises (not displayed), the $\mathrm{Au}$ deposited on the $\mathrm{S} / \mathrm{Ru}(0001)$ surface forms 3D clusters or islands instead 
of "wetting" the $\mathrm{Ru}(0001)$ surface [39]. At the same time, the STM images show that gold compresses sulphur into domains of high local coverage that favor S-S coupling and eventually lead to drastic changes in the kinetics of $S_{2}$ desorption (Figure 2) [11].

Figure 4 displays STM images for a $\mathrm{Au}$ monolayer supported on $\mathrm{Ru}(0001)$ before (left-side panel) and after (right-side panel) adsorption of sulphur [39]. Due to the mismatch between the lattices of $\mathrm{Au}$ and $\mathrm{Ru}$, the gold adlayer forms stripe domains. The image on the left shows a reconstructed Au layer of individual substrate terraces together with a second layer gold island (lower right corner). Elbows or bends that outline the domain boundary are edge dislocations where the three-fold arrangement of $\mathrm{Au}$ atoms is locally distorted to pseudo four-fold sites. Such a distorted sites should have a higher reactivity than sites of the close packed surface. And indeed, sulphur reacts preferentially with this adsorption sites, as shown by the image on the right-side panel [39]. Notice that at this stage (i.e. low sulphur coverage) only the elbows are decorated by holes created by preferential sulphur adsorption. Upon additional dosing of sulphur, STM shows a drastic change in the morphology of the system, with $\mathrm{Au}$ migrating up from the $\mathrm{Ru}$ interface and forming 3D clusters [39].

In addition to $\mathrm{Ru}(0001)$, the coadsorption of $\mathrm{S}$ and $\mathrm{Au}$ has been examined on $\mathrm{Mo}(110)$ [22], $\mathrm{Mo}(100)$ [14], $\mathrm{Rh}(111)$ [22] and $\mathrm{Pt}(111)$ [41]. In all of these substrates the interactions between $A u$ and $S$ are repulsive. The case of $\mathrm{Au} / \mathrm{Mo}(110)$ is particularly interesting since the $\mathrm{Au}-\mathrm{Mo}$ bonds are very strong with the monolayer of $\mathrm{Au}$ desorbing at $\sim 1400 \mathrm{~K}$ [22]. Nevertheless, the presence of sulphur induces breaking of these bimetallic bonds. In Figure 5, the Au desorption peaks for the $\left\{\theta_{\mathrm{Au}}>2, \theta_{\mathrm{S}}=0.74\right\} / \mathrm{Mo}(110)$ surfaces show trends and a zero-order line shape that match those of Au multilayers [22]. No signal is seen for gold attached to molybdenum. A plot of the natural logarithm of the $\mathrm{Au}$
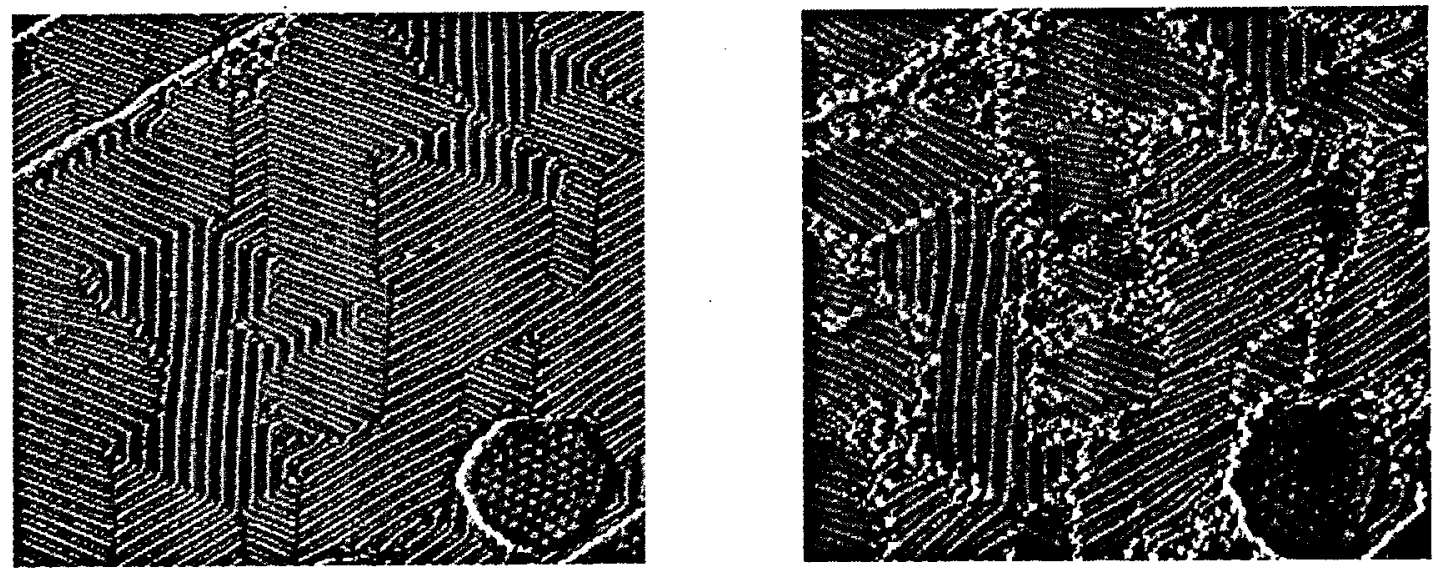

Fig 4 STM images $(300 \times 300 \mathrm{~nm})$ of a strained Au monolayer on $\mathrm{Ru}(0001)$ before (left) and after (right) coadsorption with sulfur [39]. 

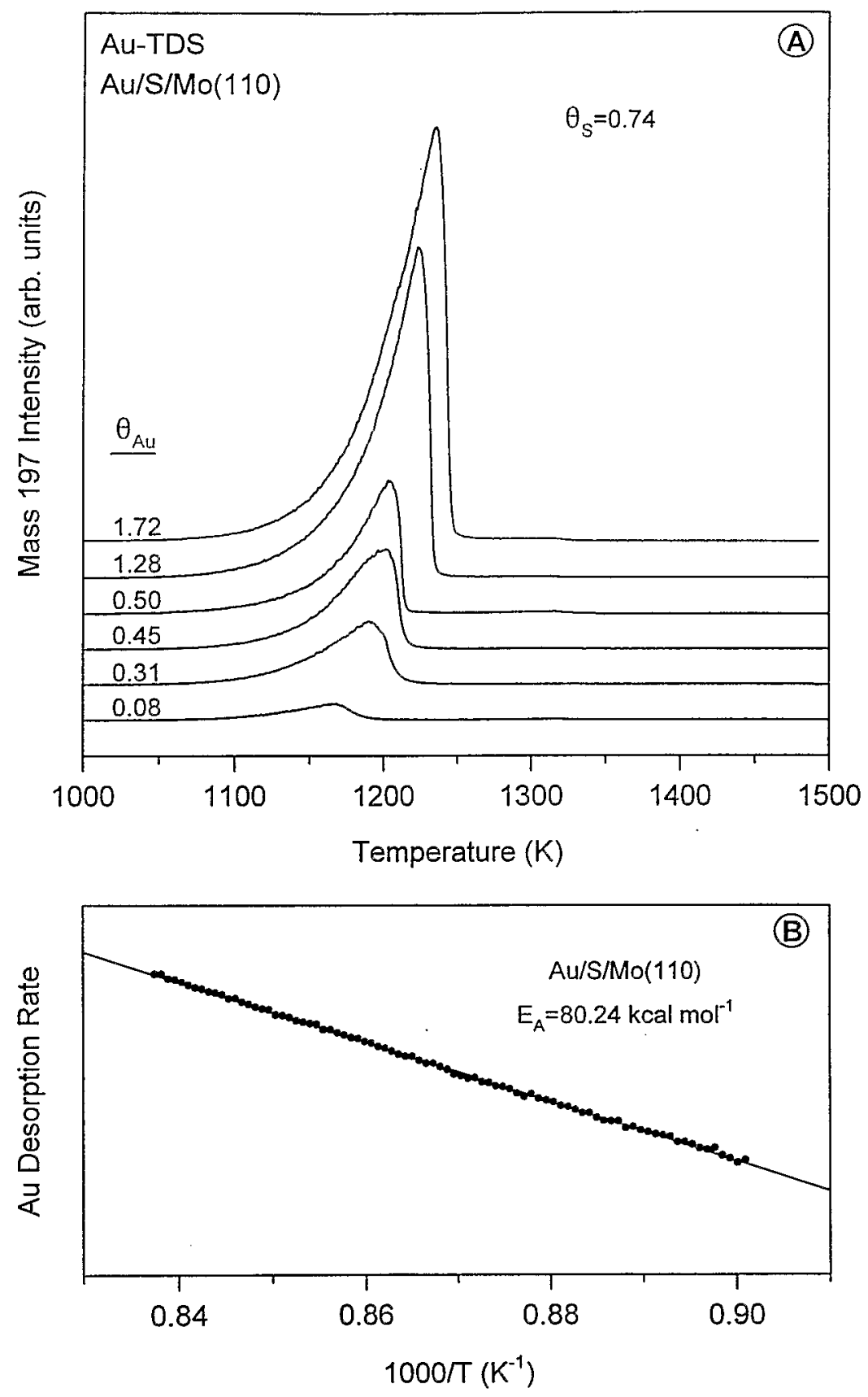

Fig 5 (A) Au-TDS spectra acquired after dosing Au to a $\mathrm{S}_{0.74} / \mathrm{Mo}(110)$ surface at $300 \mathrm{~K}$. (B) Activation energy for the desorption of gold. Reprinted from ref. [22].

desorption rate against $1 / \mathrm{T}$ yields a straight line with a desorption activation energy of $\sim 80 \mathrm{kcal} / \mathrm{mol}$. This value is close to the heat of vaporization of metallic gold [22,42]. Results of STM for the S/Au/Mo(100) system again show segregation of $\mathrm{Au}$ and $\mathrm{S}$ into separate areas of the surface [14]. 
$A b$ initio self-consistent-field calculations and cluster models have been used to study the bonding of $\mathrm{S}$ and $\mathrm{Au}$ to $\mathrm{Mo}(110)$ [22]. Both adsorbates behave as electron acceptors and, therefore, compete for the electrons of Mo. The electronic interactions between sulphur and the metal substrate are considerably stronger than those seen for the adsorption of gold. In addition to withdrawing charge from Mo atoms, sulphur substantially reduces the density-of-states (DOS) that the metal atoms exhibited around the Fermi level (highest-occupied molecular orbital, HOMO). This is illustrated in Figure 6, has been proven by photoemission spectra [43], and mainly arises from hybridisation of the $\mathrm{Mo}(4 \mathrm{~d}, 5 \mathrm{~s})$ and $\mathrm{S}(3 \mathrm{~s}, 3 \mathrm{p})$ orbitals. Such a phenomenon considerably weakens Mo-Au bonds [22].

From the studies described above, one can expect that sulphur alters (or poisons) the properties of catalysts that combine gold and transition metals by inducing a reduction in the degree of "wetting" of the surface of the transition metal by gold. This effect can explain changes induced by sulphur on the activity and selectivity of bimetallic catalysts used for hydrocarbon reforming $[7,22,30]$.
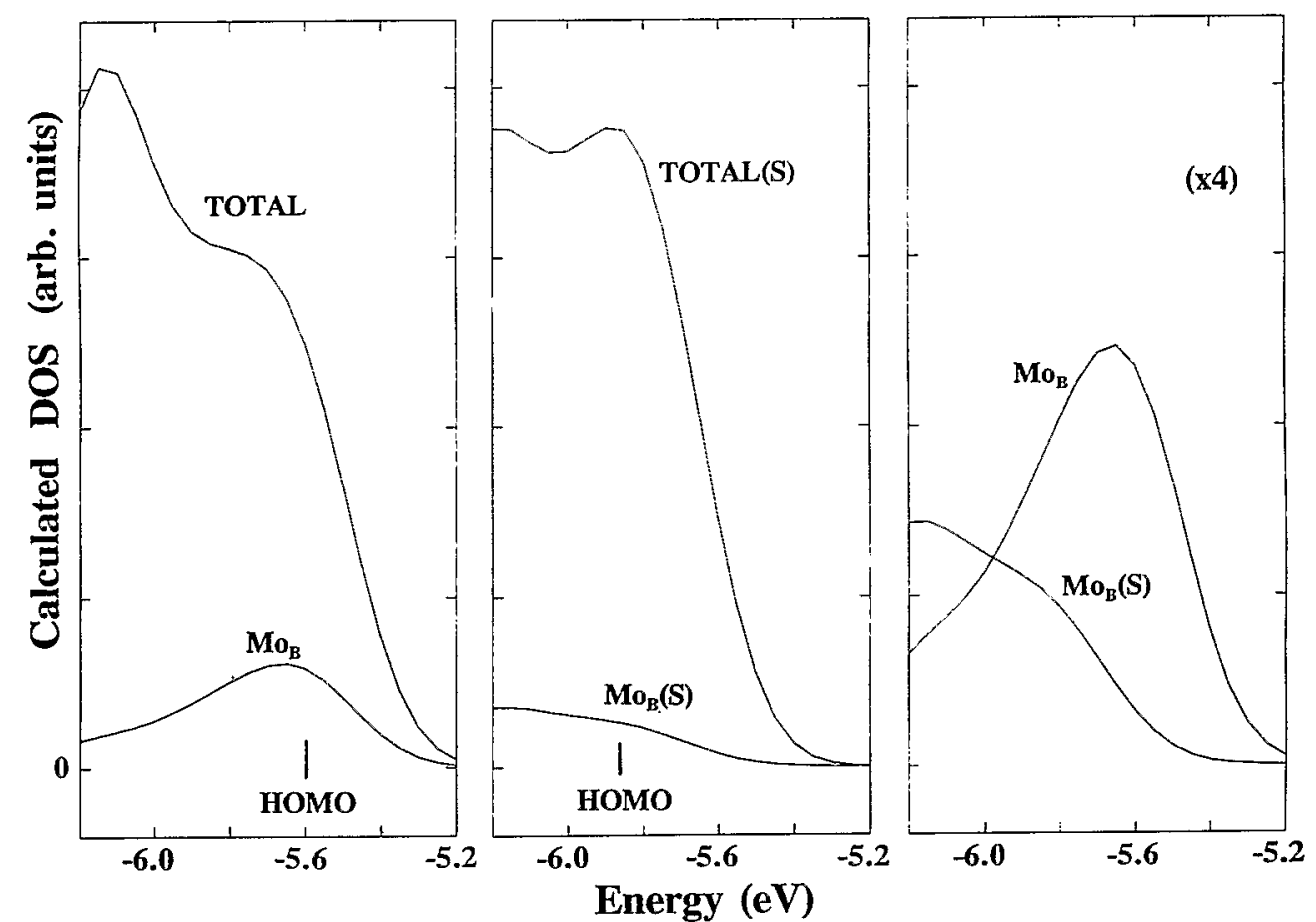

Fig 6 Calculated density-of-states (DOS) for $\mathrm{Mo}_{13}$ and S/Mo13 clusters. Only occupied states are included and the energies are reported with respect to the vacuum level. The left-side panel shows results for clean $\mathrm{Mo}_{13}$, whereas the center panel shows the corresponding values for $\mathrm{S} / \mathrm{Mo}_{13} . \mathrm{Mo}_{\mathrm{B}}$ refers to the contribution of a metal atom in a site where sulphur adsorbs. The right-side panel compares the DOS of this metal atom before and after bonding to $S$. Reprinted from ref. [22]. 


\section{Interaction of sulphur with $\mathrm{Ag} / \mathrm{Ru}(0001)$ and $\mathrm{Cu} / \mathrm{Ru}(0001)$}

Silver and copper are also used as "inert" site blockers when preparing hydrocarbon reforming catalysts $[4,7,31,33]$. With respect to sulphur, they are more reactive than gold and can form bulk sulphides [42]. Thus, when sulphur is dosed to $\mathrm{Ag} / \mathrm{Ru}(0001)$ and $\mathrm{Cu} / \mathrm{Ru}(0001)$ [13], it weakens $\mathrm{Ru}-\mathrm{Ag}$ and $\mathrm{Ru}-\mathrm{Cu}$ interactions at low coverages, but at large sulphur coverages $\mathrm{AgS}_{\mathrm{x}}$ and $\mathrm{CuS}_{\mathrm{x}}$ are formed. Figure 7 displays Ag-TDS spectra recorded after depositing silver at $300 \mathrm{~K}$ on $\mathrm{Ru}(0001)$ surfaces with different coverages of sulphur $(0,0.12,0.21$ and 0.44) [13]. The silver atoms bonded directly to clean $\mathrm{Ru}(0001)$ desorb near $1000 \mathrm{~K}$. In the presence of sulphur there is a significant weakening of the $\mathrm{Ru}-\mathrm{Ag}$ bonds. For $\left\{\theta_{\mathrm{Ag}}>0, \theta_{\mathrm{S}}>0.5\right\}$ systems, the results of Auger spectroscopy suggest the formation of $\mathrm{AgS}_{\mathrm{x}}$ on the $\mathrm{Ru}$ substrate at room temperature [13]. The top part of Figure 8 shows $\mathrm{Ag}$ - and $\mathrm{S}_{2}$-TDS spectra acquired during the thermal decomposition of a $\mathrm{Ag}_{2} \mathrm{~S}$ film generated by adsorption of $\mathrm{S}_{2}$ on a $\mathrm{Ag} / \mathrm{Ru}(0001)$ surface [13]. Desorption of a small amount of $S_{2}$ is observed between 350 and $450 \mathrm{~K}$, with most of the sulphur evolving into gas phase at temperatures from 750 to $900 \mathrm{~K}$. The $S_{2}$ desorption peak at high temperatures exhibits a line shape that is characteristic of zero-order desorption kinetics. For this peak, a plot of the desorption rate against $1 / \mathrm{T}$ yields a straight line (see Fig $8 \mathrm{~B}$ ), with an apparent activation energy of $48.8 \mathrm{kcal} / \mathrm{mol}$. This value is very close to the enthalpy of decomposition of bulk silver sulphide $\left(2 \mathrm{Ag}_{2} \mathrm{~S}_{\text {solid }} \rightarrow 4 \mathrm{Ag}_{\text {solid }}+\mathrm{S}_{2, \text { gas }}, \Delta \mathrm{H}=+46.4\right.$

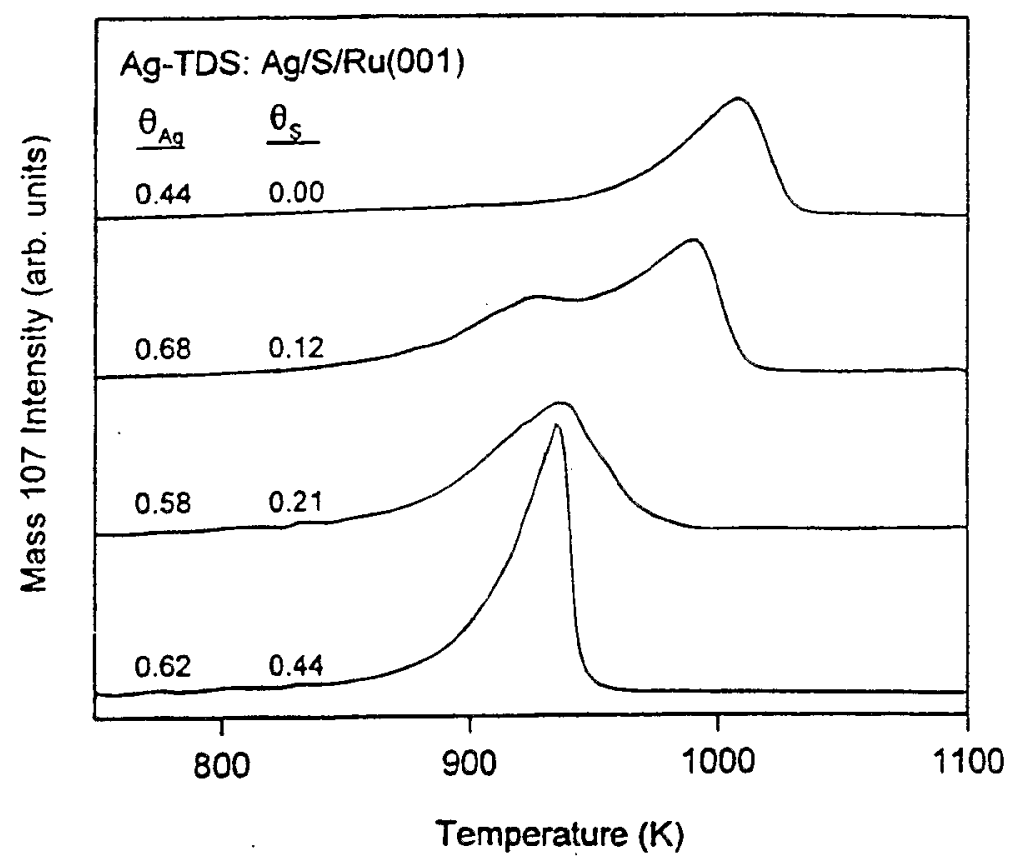

Fig 7 Ag-TDS spectra acquired after depositing silver at $300 \mathrm{~K}$ on clean $\mathrm{Ru}(0001)$ and on surfaces precovered with $0.12,0.21$, and $0.44 \mathrm{ML}$ of sulphur. Reprinted from ref. [13]. 

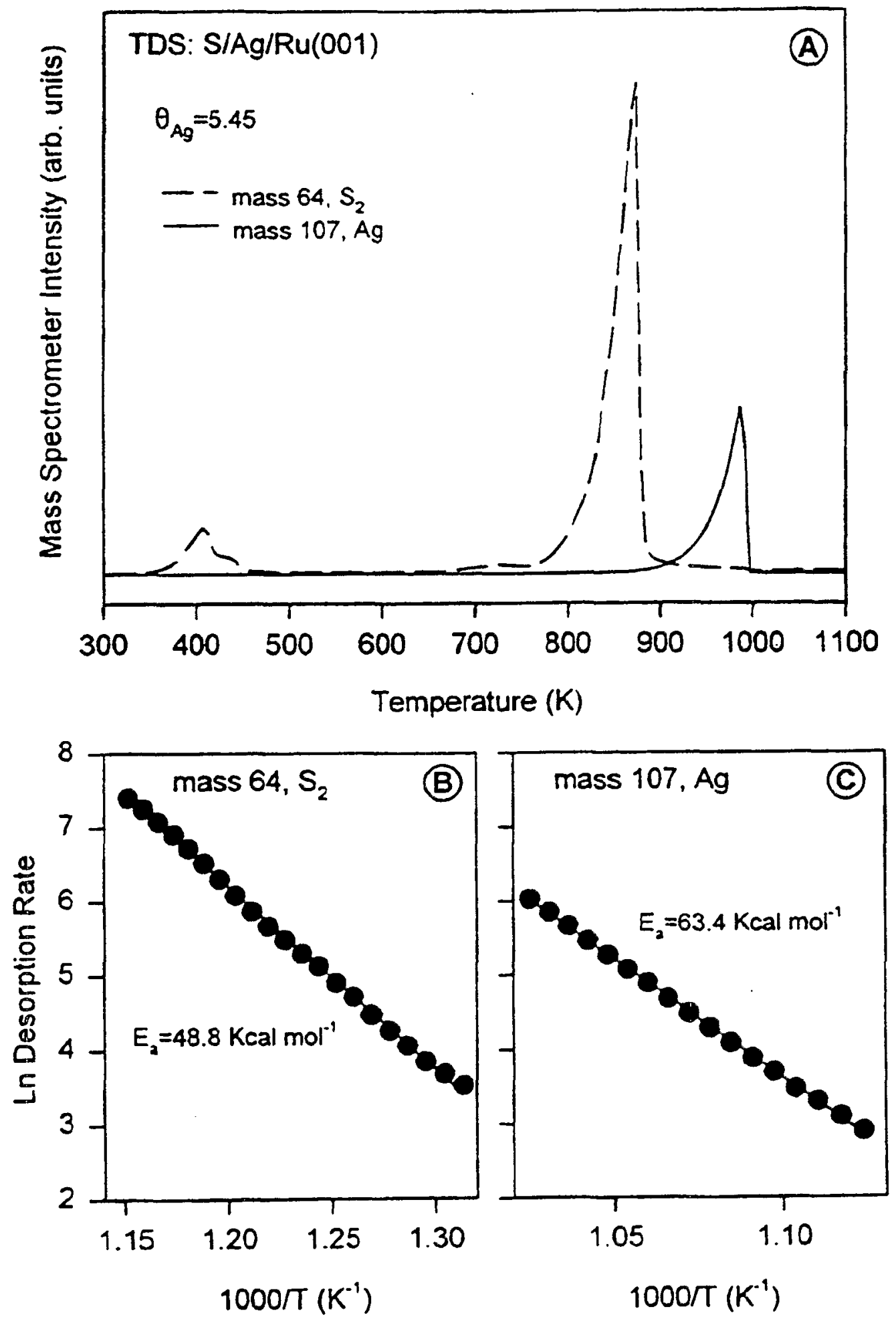

Fig 8 (A) $\mathrm{S}_{2-}$ and $\mathrm{Ag}$-TDS spectra acquired during the decomposition of a $\mathrm{Ag}_{2} \mathrm{~S}$ film generated by reaction of sulphur with a $\mathrm{Ag} / \mathrm{Ru}(0001)$ surface at $300 \mathrm{~K}$. At $1100 \mathrm{~K}$, after the thermal desorption experiment, only $0.45 \mathrm{ML}$ of $\mathrm{S}$ were left on the $\mathrm{Ru}(0001)$ surface. (B and C) Apparent activation energies for the main desorption peaks in part A. From ref. [13]. 
$\mathrm{kcal} / \mathrm{mol}$ [13]). After decomposition of the silver sulphide at $800-900 \mathrm{~K}$, a substantial amount of sulfur $(\sim 0.45 \mathrm{ML})$ remained bonded to the $\mathrm{Ru}(0001)$ surface and the $\mathrm{Ag}$ adatoms formed 3D clusters or particles. In Figure 8A, the position and shape of the $\mathrm{Ag}$ desorption peak match those observed for desorption of silver multilayers from $\mathrm{Ru}(0001)$ [36]. The graph in Figure 8C indicates that the desorption of $\mathrm{Ag}$ in Figure 8A follows zero-order kinetics with an apparent activation energy of $63.4 \mathrm{kcal} / \mathrm{mol}$. This desorption activation energy is close to the heat of vaporization of metallic silver.

Figure 9 shows an STM image recorded after adsorbing $\sim 0.1 \mathrm{ML}$ of sulphur on $\sim 0.8 \mathrm{ML}$ of silver supported on $\mathrm{Ru}(0001)$ [44]. Initially, a mismatch between the lattice parameters of $\mathrm{Ag}$ and $\mathrm{Ru}$ produced misfit dislocations in the structure of the metal overlayer (not shown) $[24,44]$. The sulphur adatoms attack preferentially these positions. Ag atoms are displaced from the $\mathrm{Ru}$ interface and their positions are occupied by sulphur atoms. Within the structure of the metal overlayer a highly ordered triangular lattice of silver vacancy islands forms (Figs

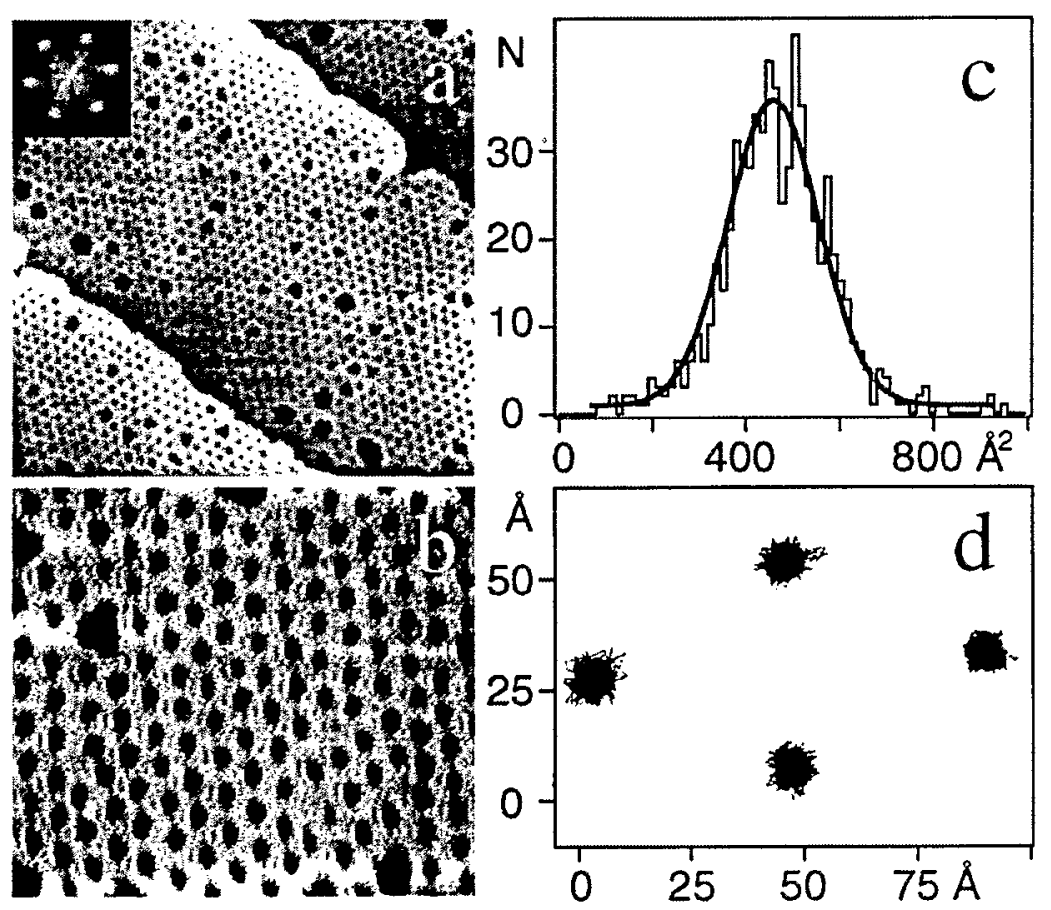

Fig 9 (a) $2000 \times 2000 \AA^{2}$ image of a S/Ag/Ru(0001) system. Three Ru terraces are shown (stepping down from the bottom left to the upper right corner). The inset shows the Fourier transform of the image. (b) A $700 \times 640 \AA^{2}$ zoom on the STM image in (a). (c) Size distribution of the vacancy islands induced by sulphur adsorption. (d) Trajectories of the center-of-mass of four neareast-neighbor vacancy islands; the positions were measured every 20 seconds. Reprinted from ref. [44]. 


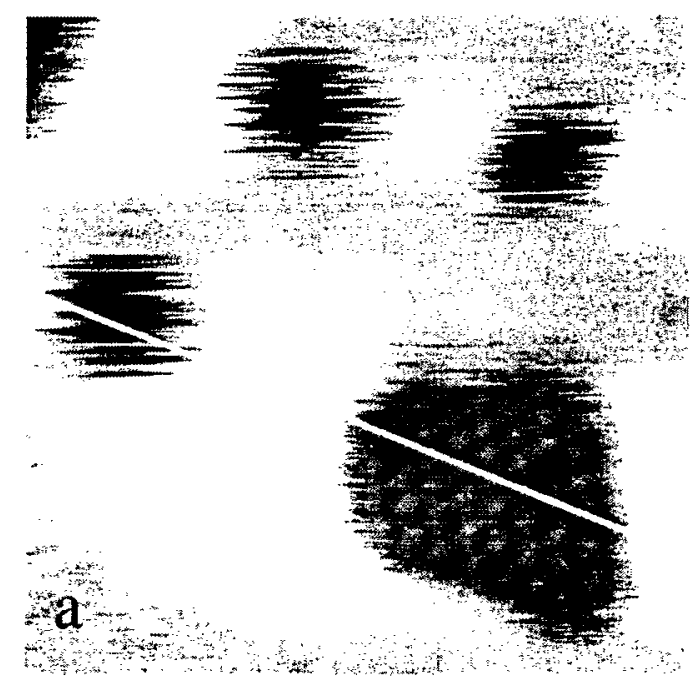

Fig 10 Atomically resolved STM image (115x115 $\AA$ ) of a large silver vacancy island, about $50 \AA$ in diameter. The island step edges of this and the smaller islands move much faster than the acquisition rate of the STM images, and thus appear "blurred". The cluster of nearly 50 sulphur adatoms inside the large island exhibits $\mathrm{p}(2 \times 2)$ order. Reprinted from ref. [44].

9a and 9b). The average area of these islands is $\sim 462 \AA$, with an standard deviation of $\sim 117 \AA$. Figure 10 displays an STM image for a typical silver vacancy island, where one can see sulphur atoms accommodated in a $\mathrm{p}(2 \times 2)$ array.

In summary, the results of TDS [13], photoemission [13,45] and STM $[24,45]$ indicate that at low sulphur coverages the interactions between $\mathrm{S}$ and $\mathrm{Ag}$ on $\mathrm{Ru}(0001)$ can be classified as repulsive, in the sense that there is weakening of the $\mathrm{Ru}-\mathrm{Ag}$ bond and no mixing of the adsorbates. Once the $\mathrm{Ru}$ substrate becomes saturated with sulphur, then attractive interactions between $\mathrm{Ag}$ and $\mathrm{S}$ are possible and $\mathrm{AgS}_{\mathrm{x}}$ is formed [13,45]. Very similar trends are observed for the coadsorption of $\mathrm{S}$ and $\mathrm{Cu}$ on $\mathrm{Ru}(0001)[13,23]$.

Figure 11 shows $\mathrm{Cu}$ - and $\mathrm{S}_{2}$-TDS spectra for the decomposition of a $\mathrm{CuS}_{\mathrm{x}}$ film on $\mathrm{Ru}(0001)$ [13]. The copper sulphide was formed after the adsorption of sulphur on a supported copper multilayer at $300 \mathrm{~K}$. The initial stoichiometry of the sulphide was $\mathrm{Cu}_{1.3} \mathrm{~S}$. An increase in temperature from 300 to $800 \mathrm{~K}$ produced desorption of a significant amount of $S_{2}$. Photoemission spectra taken after heating the sample to $800 \mathrm{~K}$ revealed that at this point a film of $\mathrm{Cu}_{2} \mathrm{~S}$ was present on top of the $\mathrm{Ru}$ substrate. This film decomposed at temperatures between 900 and $1100 \mathrm{~K}$, producing evolution of $S_{2}$ and $\mathrm{Cu}$ into gas phase (see Figure 11). After the crystal was heated to $1250 \mathrm{~K}$, only a small amount of sulphur remained on the $\mathrm{Ru}(0001)$ surface $(\sim 0.4 \mathrm{ML})$ [13].

On $\mathrm{Ru}(0001)$, the first copper layer adopts a pseudomorphic structure that reflects the lattice constant of the underlying ruthenium [46]. Because the lattice 


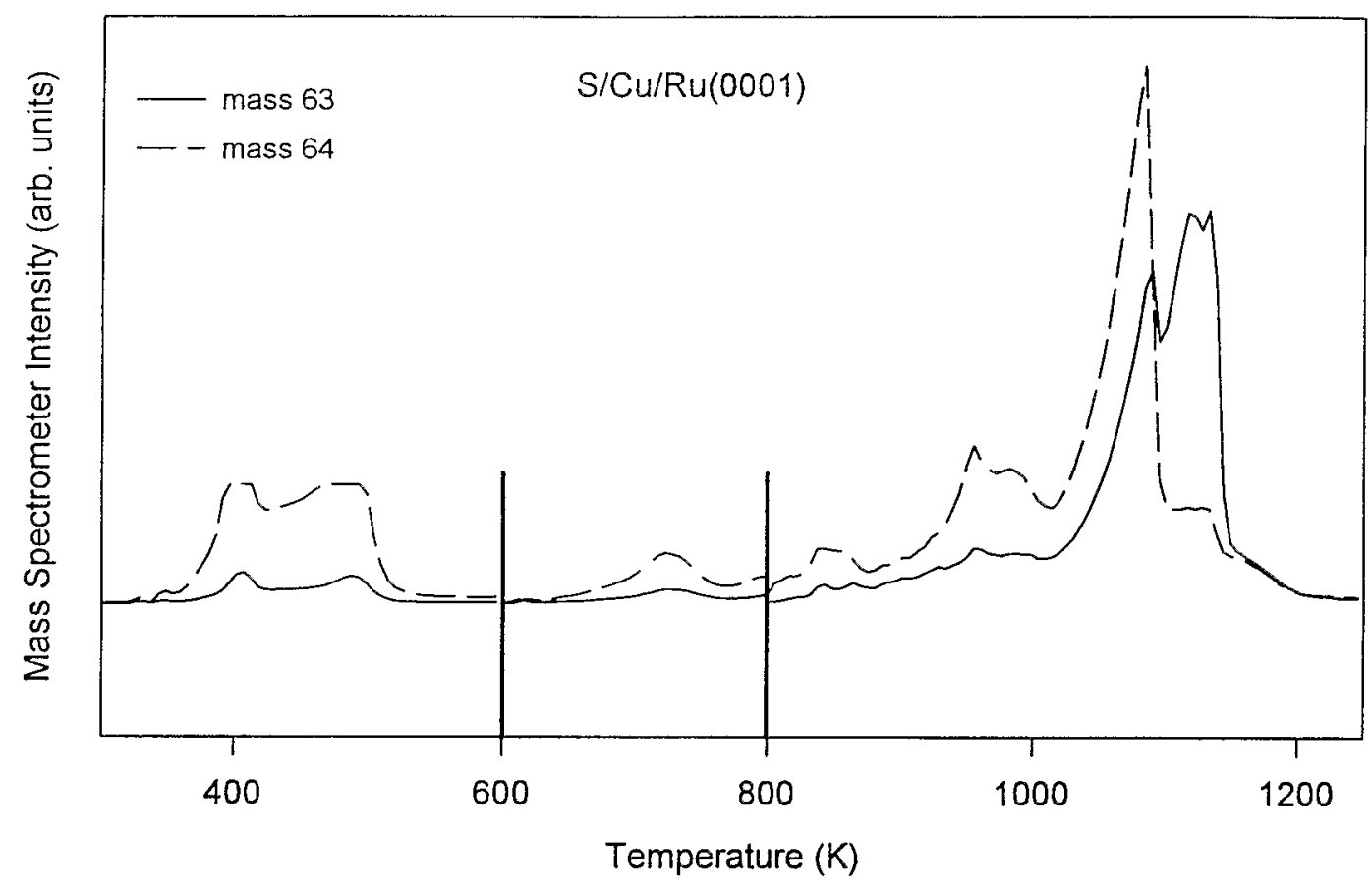

Fig $11 \mathrm{Cu}$ - and $\mathrm{S}_{2}$-TDS spectra acquired during the heating of a $\mathrm{Cu}_{1.3} \mathrm{~S}$ film to 600,800 and $1250 \mathrm{~K}$. The film was prepared by dosing sulfur to a $\mathrm{Cu}$ multilayer $\left(\theta_{\mathrm{Cu}}=4.55\right)$ at $300 \mathrm{~K}$. Reprinted from ref. [13].

constant of $\mathrm{Cu}$ is $5.5 \%$ smaller than that of $\mathrm{Ru}$, the first copper layer is under tensile strength. A sequence of strain-relieved structures develops for thicker copper films [46,47]. An anisotropically relaxed second $\mathrm{Cu}$ layer, consisting of 3 domains of double stripes is shown in Figure 12 [23]. The bright stripes are misfit dislocations buried at the $\mathrm{Cu}-\mathrm{Ru}$ interface separating regions of fcc and hcp stacking [23]. Figure 13 shows $S 2 p$ spectra after exposure of the $\sim 2 \mathrm{ML}$

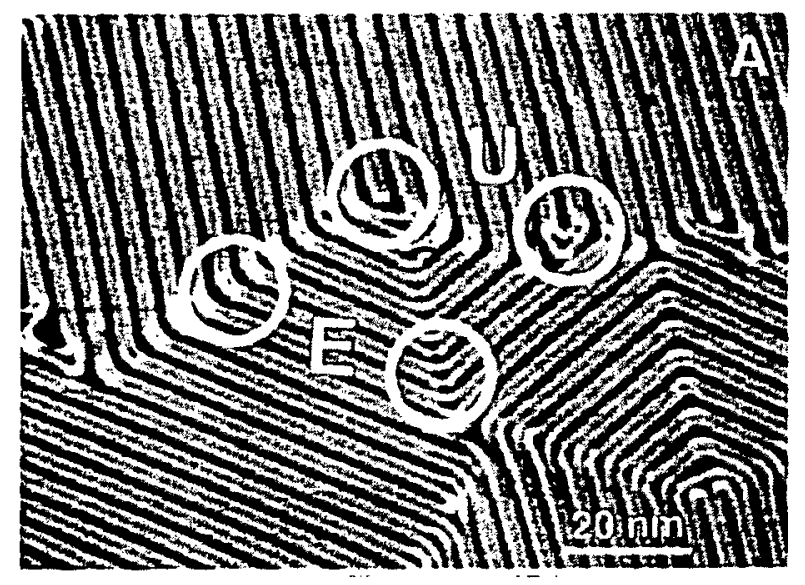

Fig 12 STM image for a $\mathrm{Cu}$ second layer on $\mathrm{Ru}(0001)$. Reprinted from ref. [23]. 


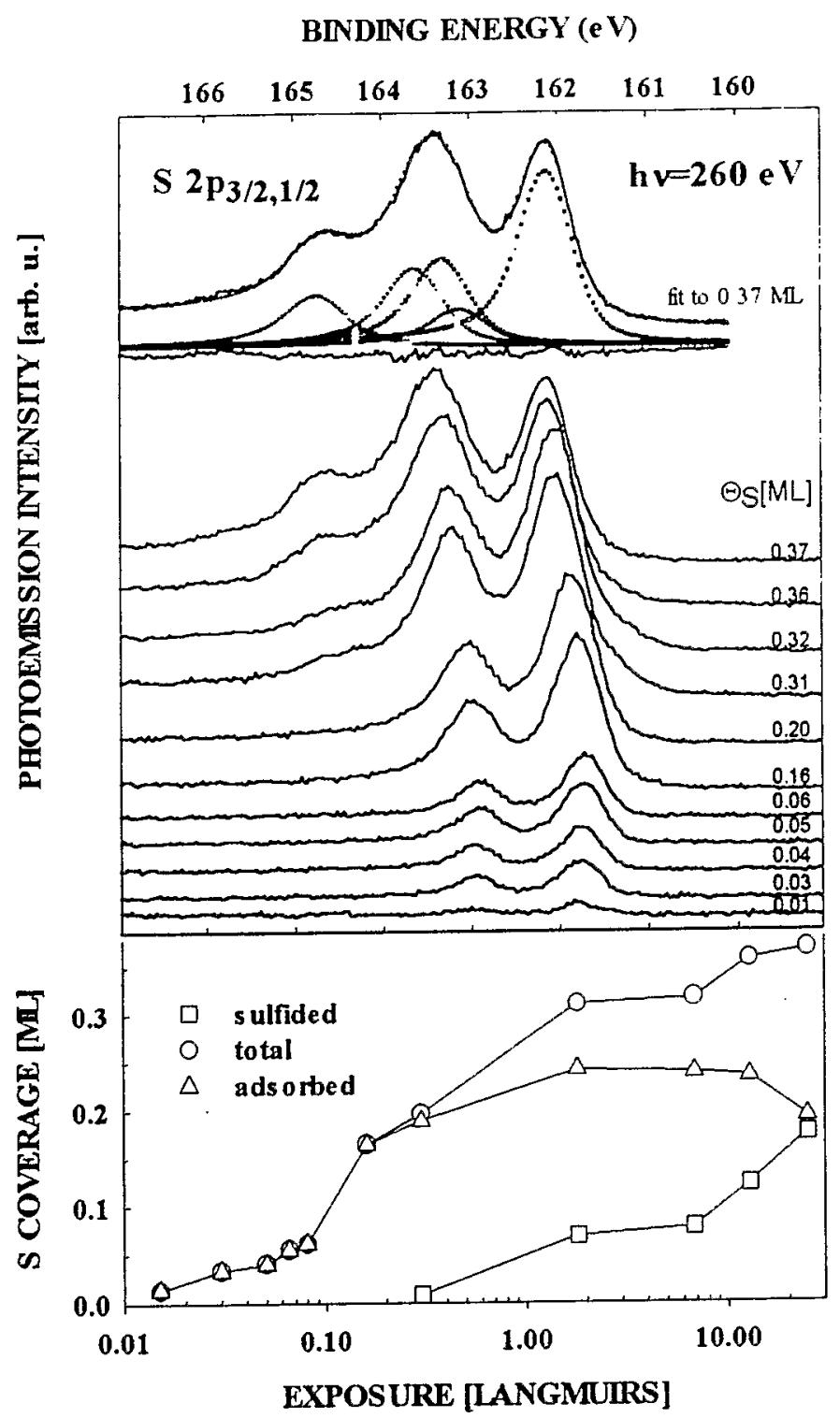

Fig $13 \mathrm{~S} 2$ p core-level spectra for the adsorption of sulphur at $300 \mathrm{~K}$ on a striped Cu layer $\left(\theta_{\mathrm{Cu}} \sim 2 \mathrm{ML}\right)$ supported on a $\mathrm{Ru}(0001)$ surface. Reprinted from ref. [23].

thick $\mathrm{Cu}$ layer to sulphur. The first spectra in the set display a well-defined $\mathrm{S}$ $2 \mathrm{p}_{3 / 2,1 / 2}$ doublet with the $2 \mathrm{p}_{3 / 2}$ component at a binding energy of $161.85 \mathrm{eV}$, an energy characteristic of adorbed atomic sulphur. The inset at the bottom of the figure shows the sulphur uptake curve based on the curve fitted and integrated experimental data. After the initial adsorption of $\sim 0.2 \mathrm{ML}$ of sulphur, a weak shoulder appears in the high binding energy side of the photoemission curve. This new feature is well defined at a sulphur coverage of $0.37 \mathrm{ML}$. Curve fitting of this spectrum (top of Fig 13) indicates that a sulphide is now present on the surface [23]. The intensity of the sulfide peak grows with increasing sulphur dose, while that of the adsorbed $\mathrm{S}$ levels off and even decreases. 
The long induction period seen in Figure 13 for the formation of the sulphide is unusual. To determine the cause, STM was used to visualize structural changes of the surface [23]. The corresponding images are shown in Figure 14 . At very low $S$ coverages $(0.001 \mathrm{ML})$, sulfur adsorbs mainly at the edge dislocations and one sees straight lines that contain 4 to 8 atoms (Figure 14A). As the coverage of sulphur increases, big morphological changes are seen in the $\mathrm{Cu}$ overlayer and new dislocations are induced by the adsorbate. At a sulphur coverage of $0.03 \mathrm{ML}$, Figures 14D and 15, the adsorbate self-organizes into a network of hexagons and close-packed equilateral S-triangles made of 18 atoms that bound the hcp stacking areas (top of Figure 15). This self-organizing network fluctuates in time (bottom of Figure 15). It disappears upon additional dosing of sulphur (not shown), well before the formation of a copper sulphide. The image quality at these higher sulphur coverages degrades and the final details of the conversion cannot be ascertained experimentally with STM [23]. Nevertheless, the results in Figures 14 and 15 illustrate quite clearly the magnitude of the structural perturbations that sulphur can induce in a bimetallic surface. Active sites for catalytic reactions can be completely destroyed in the presence of sulphur.
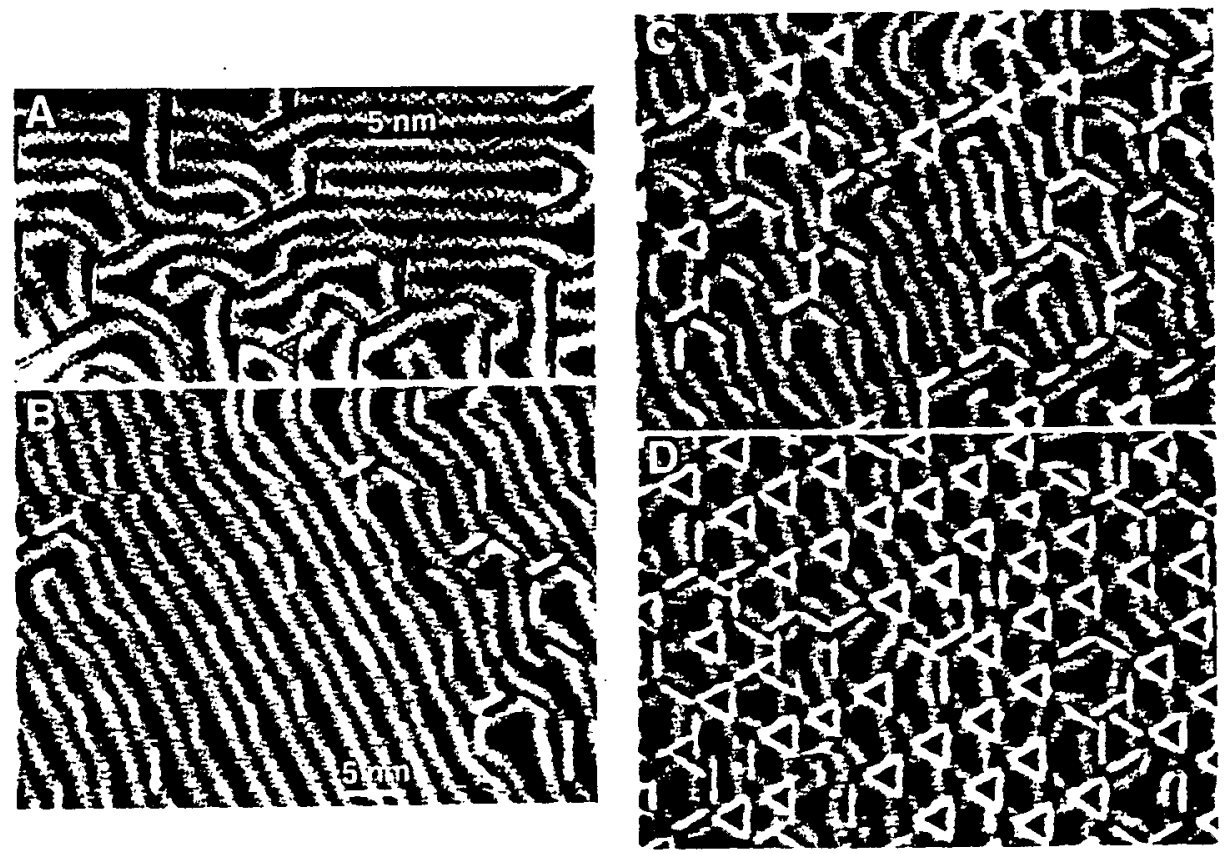

Fig 14 (A) Early stages of S adsorption on the stripped $\mathrm{Cu}$ layer. Individual $\mathrm{S}$ adatoms images as black dots are arranged in short rows and are found at the edge dislocations and less frequently on stripes. Estimated S coverage $<0.01 \mathrm{ML}$. (B-D) Development of sulphur features with increasing $S$ coverage: sulphur adatoms self-organize in rows, hexagons, and equilateral triangles. Sulphur rows can be imaged as dark or bright lines depending on the tip status. Reprinted from ref. [23]. 


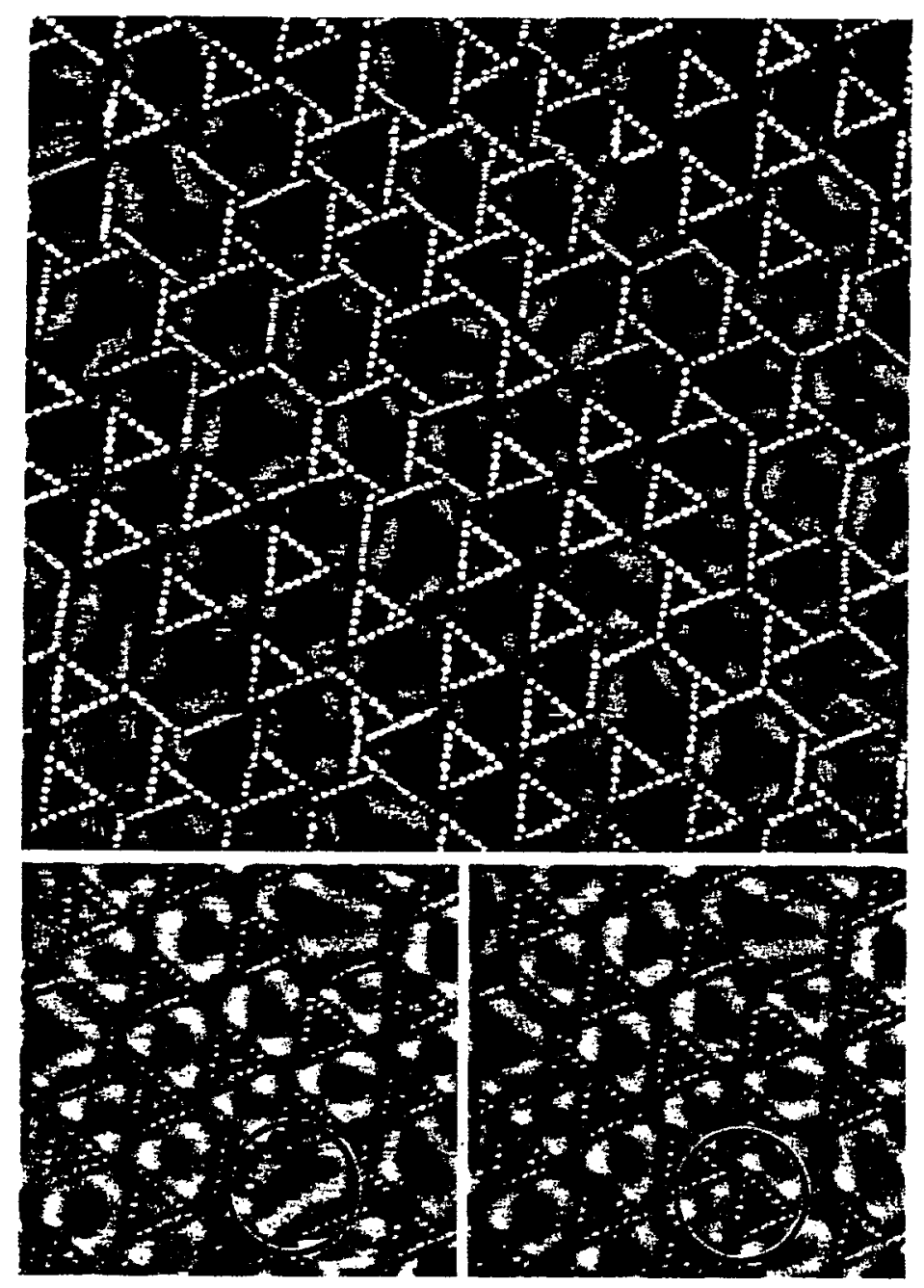

Fig 15 An image $(7.3 \mathrm{~nm} \times 6.9 \mathrm{~nm})$ of S self-organized in hexagons and equilateral triangles made of 18 sulphur adatoms. At room temperature and fixed $\mathrm{S} / \mathrm{Cu}$ stoichiometry $\left(\theta_{\mathrm{Cu}} \sim 0.03\right.$ ML for this image) the observed structural patterns fluctuate for hours. Lower two time-lapse images $(3.5 \mathrm{~nm} \times 3.3 \mathrm{~nm})$ taken $50 \mathrm{~s}$ apart show formation of new equilateral triangles. Reprinted from ref.[23].

\section{Admetal promoted sulfidation of $\operatorname{Pt}(111)$ and $M o(110)$}

A large number of studies described in this book indicate that the formation of a heteronuclear metal-metal bond can lead to important changes in the chemical properties of the bonded elements. In many cases, bimetallic bonding induces a large redistribution of charge around the metals [48-50]. In principle, this redistribution of charge could affect the reactivity of a metal toward sulfur. 
A very interesting situation is found when $\mathrm{Ag}$ or $\mathrm{Cu}$ are added to $\mathrm{Pt}(111)$ $[15,17,41]$. Figure 16 compares Pt $4 \mathrm{f}$ XPS spectra acquired before and after dosing $S_{2}$ to $\mathrm{Pt}(111)$ and a $\mathrm{Ag} / \mathrm{Pt}(111)$ system with $2.26 \mathrm{ML}$ of the admetal [17]. The exposure of $\mathrm{Pt}(111)$ to large amounts of $S_{2}$ produces only a chemisorbed layer of $\mathrm{S}$, without forming bulk-like sulphides which are thermodynamically very stable $\left(\mathrm{PtS}_{2}, \Delta \mathrm{G}_{\mathrm{f}}=-109 \mathrm{~kJ} / \mathrm{mol}\right.$ [42]). For the $\mathrm{S} / \mathrm{Pt}(111)$ system, two factors make difficult the penetration of $S$ into the bulk of the metal. First, the surface free energy of sulphur $\left(0.08 \mathrm{~J} \mathrm{~m}^{-2}\right.$ [51]) is much lower than that of platinum (2.69 $\mathrm{J} \mathrm{m}^{-2}$ [51]). And second, the cohesive energy of metallic Pt is relatively large $(564 \mathrm{~kJ} / \mathrm{mol}[52])$. If the influence of these two factors is somehow suppressed, then, the formation of platinum sulphides should take place. In Figure 16, new $\mathrm{Pt} 4 \mathrm{f}$ features for platinum sulphide are detected after dosing $\mathrm{S}_{2}$ to a $\mathrm{Ag} / \mathrm{Pt}(111)$ surface. The relative large intensity of these features indicates that a big amount ( $>1 \mathrm{ML})$ of $\mathrm{PtS}_{\mathrm{x}}$ is formed [17]. Silver has a relatively low surface free energy $\left(1.30 \mathrm{~J} \mathrm{~m}^{-2}[51]\right)$, and its presence on the Pt surface probably frees sulphur for migration into the bulk of the sample. In the Ag-Pt(111) bond there is a significant shift of electrons from the admetal toward the metal substrate [50,53] that favors the formation of $\mathrm{Pt} \rightarrow \mathrm{S}$ dative bonds. In addition, silver sulphides could promote the formation of platinum sulphides by inducing changes in the structural geometry that enhance the diffusion of sulfur into the lattice of metallic platinum [17]. Figure 17 displays photoemission data for

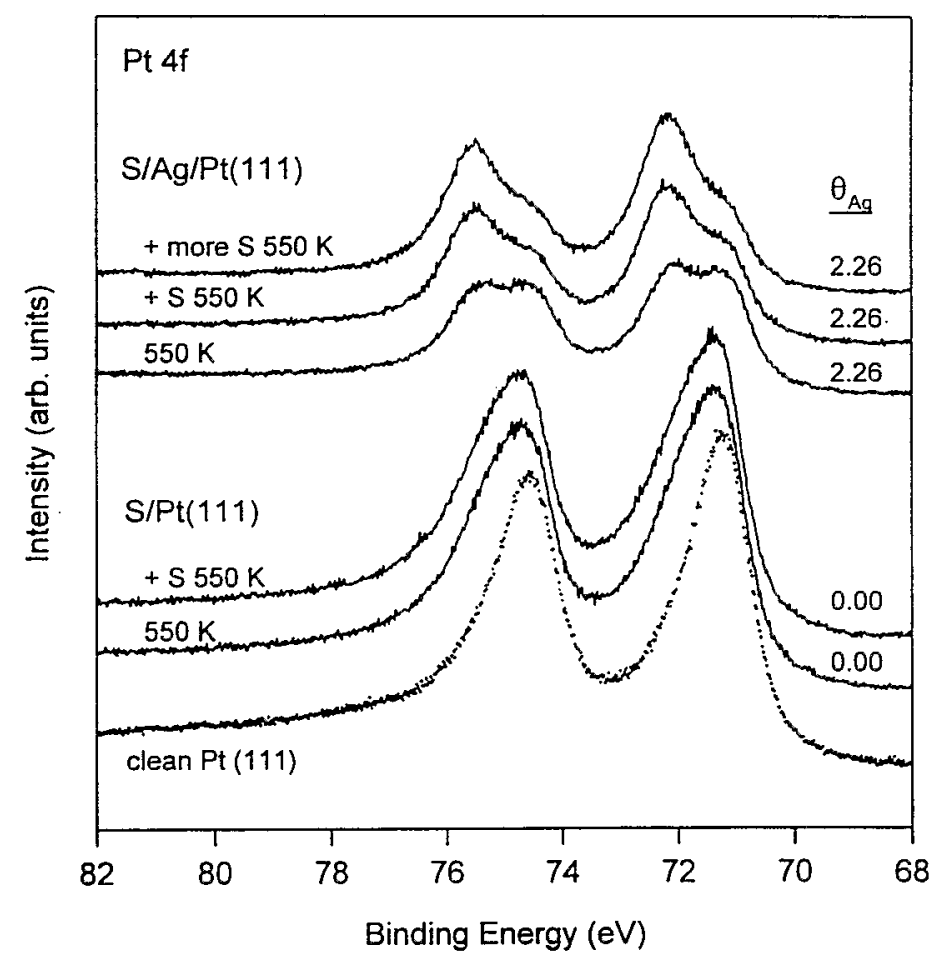

Fig $16 \mathrm{Pt}$ 4f XPS spectra acquired after doing $S_{2}$ to $\mathrm{Pt}(111)$, bottom, and $\mathrm{Ag} / \mathrm{Pt}(111)$ surfaces, top. Reprinted from ref. [17]. 


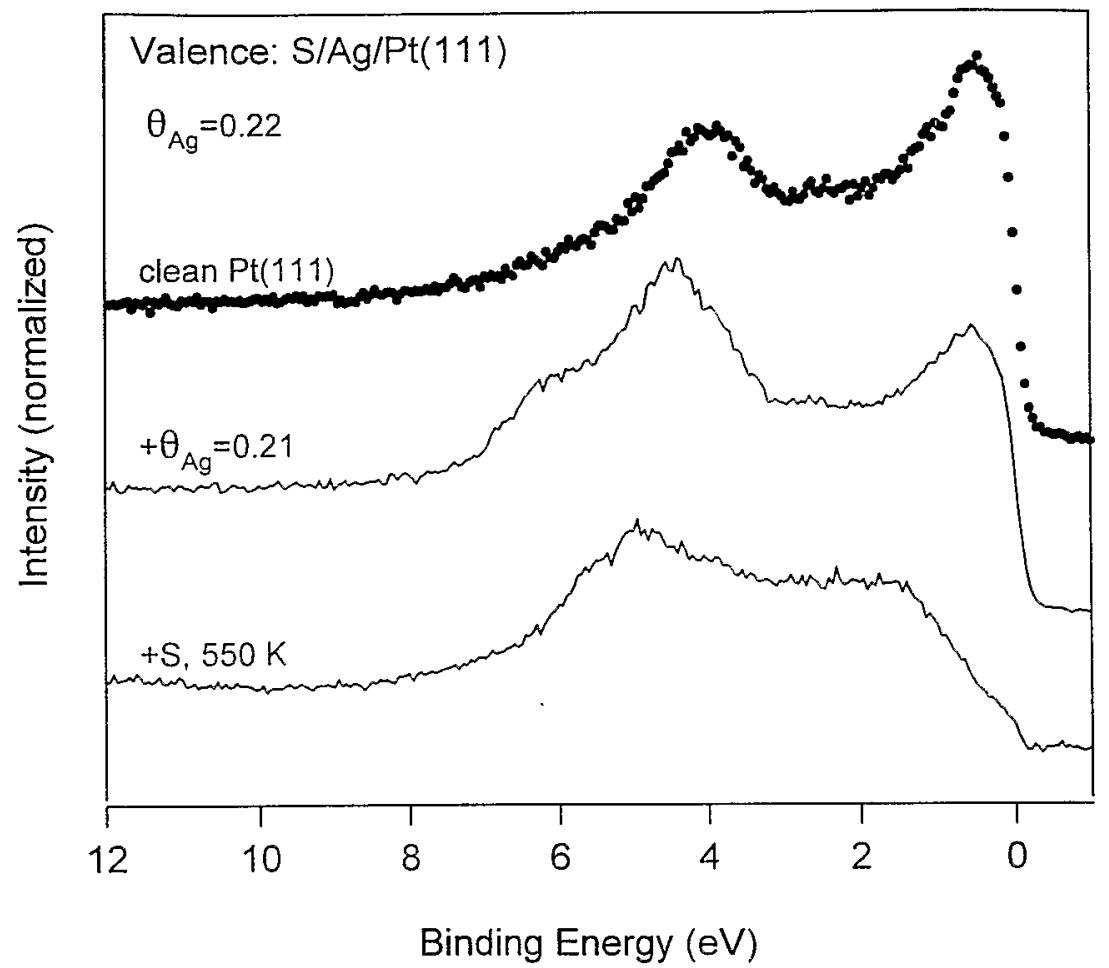

Fig 17 Valence photoemission data for $\mathrm{Pt}(111), \mathrm{Ag} / \mathrm{Pt}(111)$ and $\mathrm{S} / \mathrm{Ag} / \mathrm{Pt}(111)$ surfaces. Initially, 0.21 $\mathrm{ML}$ of silver were vapor-deposited at $\sim 300 \mathrm{~K}$, and the $\mathrm{Ag} / \mathrm{Pt}(111)$ surface was annealed to $550 \mathrm{~K}$ before dosing $\mathrm{S}_{2}$ at this temperature. Reprinted from ref. [41].

the valence region of $\mathrm{Pt}(111), \mathrm{Ag} / \mathrm{Pt}(111)$ and $\mathrm{S} / \mathrm{Ag} / \mathrm{Pt}(111)$ [41]. $\mathrm{Pt}(111)$ and $\mathrm{Ag} / \mathrm{Pt}(111)$ exhibit a substantial DOS near the Fermi level and are chemically and catalytically active. The silver-induced formation of $\mathrm{PtS}_{\mathrm{x}}$ in $\mathrm{S} / \mathrm{Ag} / \mathrm{Pt}(111)$ leads to a very large drop in the DOS around the Fermi level, hindering the ability of the system to respond to the presence of adsorbates. Thus silver, ideally added as an inert site blocker to reduce C-C hydrogenolysis on $\mathrm{Pt}$ reforming catalysts [31-33], can actually accelerate the rate of sulfur poisoning.

Copper also promotes the rate of sulfidation of platinum [15], but not all the admetals used as site blockers $(\mathrm{Zn}, \mathrm{Al}, \mathrm{Sn})$ in Pt-based reforming catalysts behave in this way $[15,25,26,29]$. Figure 18 shows $\mathrm{Pt} 4 \mathrm{f}$ spectra acquired after adsorbing sulphur on $\mathrm{Pt}(111)$ and several bimetallic systems. Strong peaks are seen for $\mathrm{PtS}_{\mathrm{x}}$ in $\mathrm{S} / \mathrm{Ag} / \mathrm{Pt}(111)$ [17] and $\mathrm{S} / \mathrm{Cu} / \mathrm{Pt}(111)$ [15]. No platinum sulphide formation is observed for $\mathrm{S} / \mathrm{Zn} / \mathrm{Pt}(111)$ [15] and $\mathrm{S} / \mathrm{Al} / \mathrm{Pt}(111)$ [25]. In $\mathrm{Zn}-\mathrm{Pt}$ and Al-Pt bonds there is a net charge transfer toward Pt [54-56] that should facilitate the formation of $\mathrm{Pt} \rightarrow \mathrm{S}$ dative bonds. In addition, $\mathrm{Zn}$ and $\mathrm{Al}$ (like $\mathrm{Ag}$ and $\mathrm{Cu}$ ) have a smaller surface free energy than $\mathrm{Pt}$ [51]. However, the $\mathrm{Zn}-\mathrm{Pt}$ (or $\mathrm{Al}-\mathrm{Pt}$ ) bonds break apart in the presence of $S$ and the $P t \leftrightarrow \mathrm{ZnS}_{\mathrm{x}}\left(\right.$ or $P t \leftrightarrow \mathrm{AlS}_{\mathrm{x}}$ ) interactions are weak. After analysing the results in Figure 18, one can conclude that an 
admetal $\rightarrow$ Pt charge transfer and a low surface-free energy for the admetal may be necessary, but insufficient conditions for seeing a promotional effect of the admetal on the formation of platinum sulphides [25]. On the other hand, the relative stabilities of the admetal sulphides may have a direct impact on whether or not sulfidation of the Pt substrate will occur. In bimetallic systems where the admetals form sulphides of higher stability than those formed by platinum $(\mathrm{Zn} / \mathrm{Pt}$ and $\mathrm{Al} / \mathrm{Pt})$ [42], the adsorption of sulphur stops once the admetal is saturated with sulphur and no $\mathrm{PtS}_{\mathrm{x}}$ is formed. Not included in Figure 18 are data for the $\mathrm{S} / \mathrm{Sn} / \mathrm{Pt}(111)$ system [26]. In this special system, bimetallic bonding actually reduces the reactivity of both metals toward sulphur [26-28]. This can be useful for the prevention of sulphur poisoning and will be the subject of section 5 .

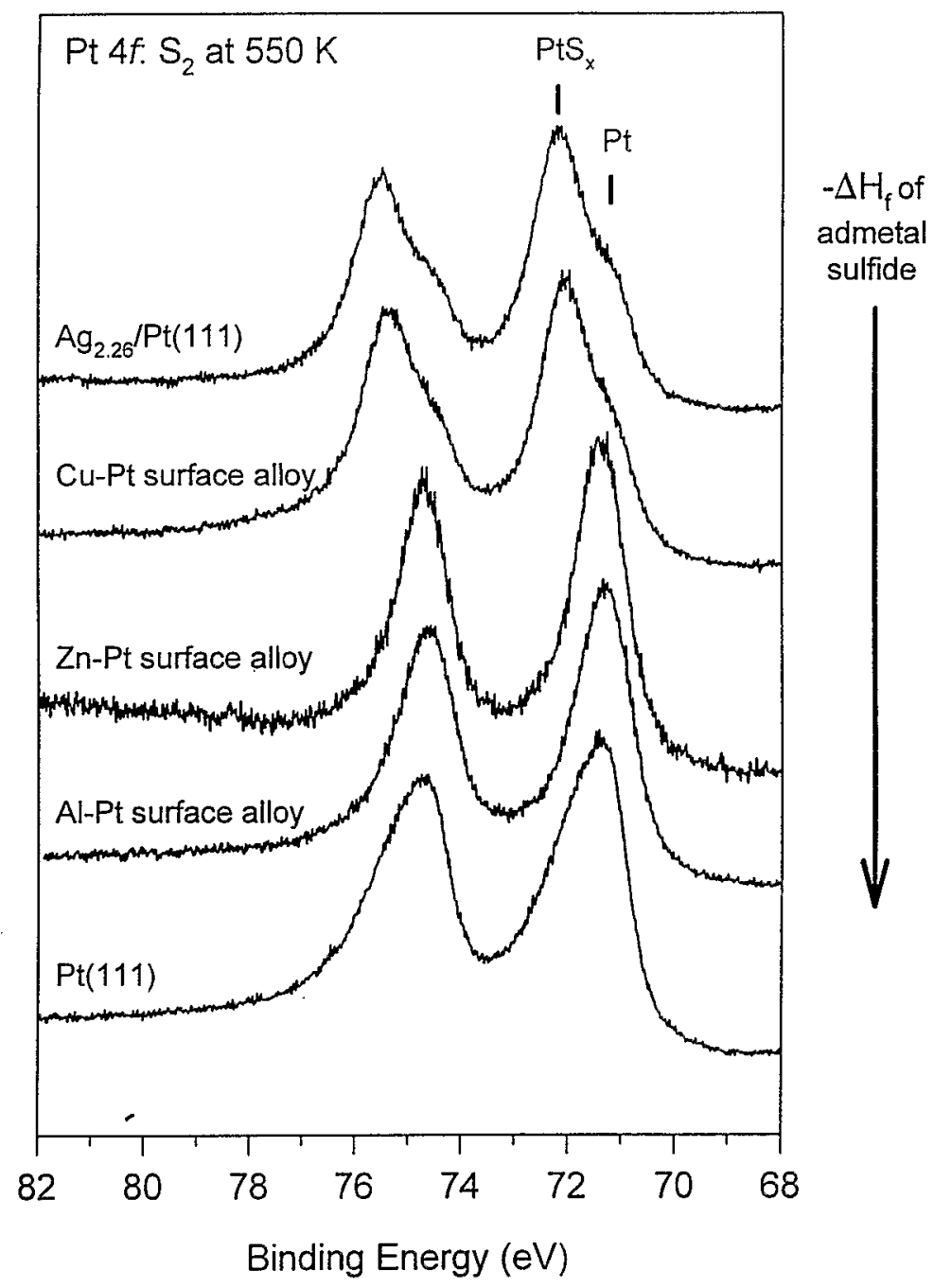

Fig $18 \mathrm{Pt} 4 \mathrm{f}$ XPS results comparing the effect of dosing $S_{2}$ at $550 \mathrm{~K}$ to clean $\mathrm{Pt}(111)$ and a series of $\mathrm{X} / \mathrm{Pt}$ systems $\{\mathrm{X}=\mathrm{Ag}, \mathrm{Cu}, \mathrm{Zn}$ and $\mathrm{Al}\}$. The heat of formation for the sulphides of the admetals increases (more exothermic) when going from the top to the bottom of the figure. Reprinted from ref. [25]. 
The sulfidation of $\mathrm{Mo}(110)$ is promoted by a series of admetals ( $\mathrm{Fe}, \mathrm{Co}, \mathrm{Ni}$, $\mathrm{Cu}, \mathrm{Ag}$ and $\mathrm{Zn})[19,20,57,58]$ that form sulphides that are less stable than those formed by molybdenum [42]. Figure 19 displays Mo 3d XPS spectra acquired upon dosing $S_{2}$ to $M o(110)$ and $M o(110)$ surfaces with similar coverages $(\sim 1.5$ $\mathrm{ML}$ monolayers ) of $\mathrm{Ni}$ [19], $\mathrm{Cu}$ [16], $\mathrm{Zn} \mathrm{[20]} \mathrm{and} \mathrm{Ag}$ [16]. These and other results $[57,58]$ indicate that the amount of $\mathrm{MoS}_{\mathrm{x}}$ formed depends strongly on the nature of the admetal. Specifically, $\mathrm{Ni}$ and Co have a unique ability to promote $\mathrm{Mo}-\mathrm{S}$ interactions and the formation of molybdenum sulfide [19,57,58]. Results for the reaction of $S_{2}$ with a series of $X / M o(110)$ surfaces $(X=$ admetal) indicate that the "promotional effect" of an admetal increases following the sequence: $\mathrm{Ag}$ $\approx \mathrm{Zn}<\mathrm{Cu}<\mathrm{Fe}<\mathrm{Co}<\mathrm{Ni}[19,57,58]$.

Figure 20 compares trends observed in the activity of a series of XS $/ \mathrm{MoS}_{2}$

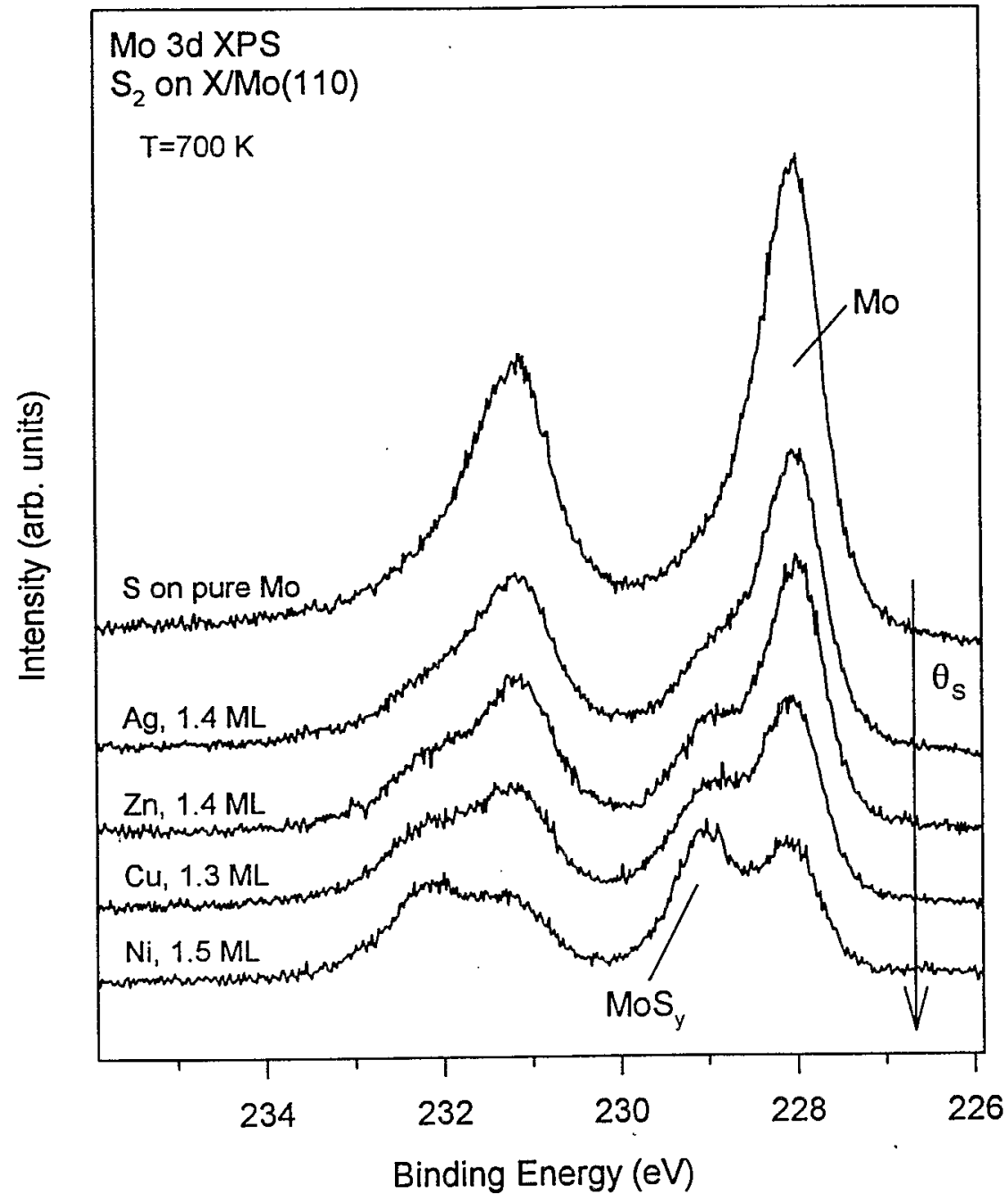

Fig 19 Mo 3d XPS spectra acquired after dosing large amounts of $S_{2}$ to clean $\mathrm{Mo}(110)$ and $\mathrm{X} / \mathrm{Mo}(110)$ surfaces $(\mathrm{X}=\mathrm{Ag}, \mathrm{Zn}, \mathrm{Cu}$ or $\mathrm{Ni})$ at $700 \mathrm{~K}$. The spectra correspond to systems in which the rate of $S_{2}$ adsorption has become zero under UHV conditions. Reprinted from ref. [19]. 


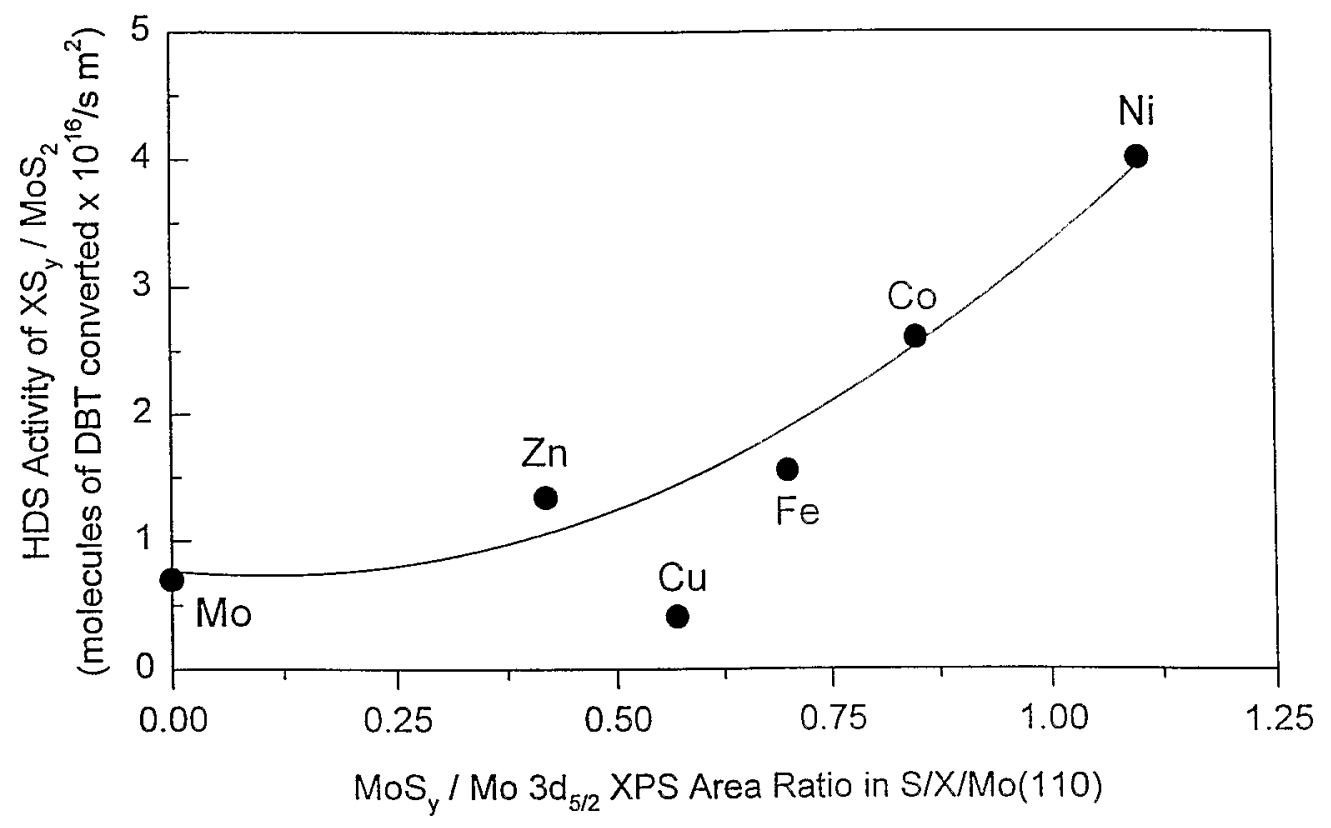

Fig $20 \mathrm{X}$ axis: relative amount of $\mathrm{MoS}_{\mathrm{y}}$ formed after exposing $\mathrm{X}_{1.5} / \mathrm{Mo}(110)$ surfaces $(\mathrm{X}=$ $\mathrm{Zn}, \mathrm{Cu}, \mathrm{Fe}, \mathrm{Co}$ and $\mathrm{Ni}$, with $\theta_{x}=1.5 \mathrm{ML}$ ) to $S_{2}$ at $700 \mathrm{~K}$ Y axis: activity of $\mathrm{MoS}_{2}$ and $\mathrm{XS}_{\mathrm{y}} / \mathrm{MoS}_{2}$ catalysts for the hydrodesulfurization of dibenzothiophene (DBT). Reprinted from ref. [61].

catalysts $(\mathrm{X}=\mathrm{Zn}, \mathrm{Cu}, \mathrm{Fe}, \mathrm{Co}$ or $\mathrm{Ni})$ during the hydrodesulfurization of dibenzothiophene $[59,60]$ with trends found for the sulfidation of molybdenum in $\mathrm{X} / \mathrm{Mo}(110)$ surfaces $[19,58,61]$. In general, a good correlation is observed between the changes in the two chemical properties. The presence of Ni leads to a significant enhancement in the $\mathrm{Mo} \rightarrow \mathrm{S}$ interactions and a very large HDS activity. In contrast, the effects of $\mathrm{Zn}, \mathrm{Cu}$, and $\mathrm{Fe}$ on the $\mathrm{Mo} \rightarrow \mathrm{S}$ interactions and HDS activity are less pronounced. From the correlation in Figure 20, it is clear that the effects of bimetallic bonding can be useful in HDS catalysis. Three factors probably contribute to the large HDS activity of $\mathrm{NiMoS}_{\mathrm{x}}$ catalysts [19,58,61]: (1) the existence of $\mathrm{Ni}$ centers that have S-free sites on which a Scontaining molecule can adsorb; (2) the presence of Ni-Mo sites that are very reactive for the desulfurization of the adsorbed molecule; and (3) on the S-free Ni sites hydrogen molecules can dissociate, producing in this way a source of hydrogen atoms that helps to remove sulphur from the surface and keeps a large number of unsaturated $\mathrm{Mo}$ and $\mathrm{Ni}$ sites.

$\mathrm{Ag} / \mathrm{Mo}(110)$ and $\mathrm{Zn} / \mathrm{Mo}(110)$ are very useful for the synthesis of $\mathrm{MoS}_{\mathrm{x}}$ films under UHV conditions [16,20,57,61]. The dosing of $\mathrm{S}_{2}$ to $\mathrm{Ag} / \mathrm{Mo}(110)$ and $\mathrm{Zn} / \mathrm{Mo}(110)$ produces bimetallic sulfides, but upon heating to $1000-1100 \mathrm{~K}$ the silver and zinc desorb, leaving films of pure $\mathrm{MoS}_{\mathrm{x}}$ on top of the $\mathrm{Mo}(110)$ substrate. Following this methodology, films that have between 2 and 6 sulphide 
monolayers can be prepared. The films exhibit Mo $3 \mathrm{~d}$ and S 2p XPS spectra that are very similar to those of $\mathrm{MoS}_{2}$. They show no reactivity toward $\mathrm{CO}, \mathrm{O}_{2}$ or $\mathrm{H}_{2}$ at $100-400 \mathrm{~K}$. But they can be activated after the creation of $\mathrm{S}$ vacancies by reaction with atomic $\mathrm{H}$ [62], providing convenient surfaces for examining the chemistry of desulfurization reactions on molybdenum sulfide [63].

\section{Bimetallic bonding and the prevention of sulfur poisoning}

In the previous section we have discussed several cases in which bimetallic bonding increases the overall reactivity of a system towards sulphur. If the opposite occurs, such a phenomenon could be useful for the prevention of sulphur poisoning. In practical terms, the idea is to find bimetallic systems that have a good catalytic activity and are less sensitive to the presence of sulphurcontaining molecules in the feedstream than pure metals. $\mathrm{Sn} / \mathrm{Pt}$ and $\mathrm{Pd} / \mathrm{Rh}$ satisfy these requirements [26-29].

Pt-Sn bimetallic catalysts are widely used for hydrocarbon reforming or dehydrogenation reactions $[4,5,64-66]$. In $\mathrm{Sn} / \mathrm{Pt}$ alloys, there is a redistribution of charge and both metals accumulate electrons around the Pt-Sn bonds [26,6769]. The effects of bimetallic bonding on the chemical properties are very dramatic in the case of tin $[26,27]$. In the presence of $S_{2}$, tin does not get fully sulphided as other metals $(\mathrm{Al}, \mathrm{Zn}, \mathrm{Cu}, \mathrm{Ag})$ do when they are supported on $\operatorname{Pt}(111)[15,17,25]$. The formation of Sn-Pt bonds reduces the electron density of tin and the metal has difficulties responding to the presence of sulphurcontaining molecules $[26,27,29]$. The bottom of Figure 21 compares the uptake of sulphur and $\mathrm{SO}_{\mathrm{x}}$ species after dosing $\mathrm{SO}_{2}$ to polycrystalline $\mathrm{Sn}, \mathrm{Pt}(111)$, and a $(\sqrt{3} \times \sqrt{3}) \mathrm{R} 30^{\circ}-\operatorname{Sn} / \operatorname{Pt}(111)$ surface alloy [27]. The top of the figure shows the structural geometry of the $\mathrm{Sn} / \mathrm{Pt}$ alloy. Sn atoms are present only in the top layer and protrude $0.22 \AA$ out of the plane of $\mathrm{Pt}$ atoms [70,71]. Each Pt atom present in the surface has the same number of $\mathrm{Pt}$ and $\mathrm{Sn}$ neighbours ( 3 and 3 ). In the alloy, there are plenty of a-top and bridge Pt sites that can adsorb and dissociate a small molecule like $\mathrm{SO}_{2}$. Figure 21 indicates that pure tin is much more reactive than pure platinum. In fact, photoemission studies indicate that even at temperatures as low as $100 \mathrm{~K}$, tin reacts vigorously with $\mathrm{SO}_{2}$ [27]. Therefore, one could expect that $\mathrm{Sn}$ adatoms would enhance the ability of the $\mathrm{Pt}(111)$ surface to adsorb and dissociate $\mathrm{SO}_{2}$. However, the $(\sqrt{3} \mathrm{x} \sqrt{3}) \mathrm{R} 30^{\circ}-\mathrm{Sn} / \mathrm{Pt}(111)$ surface alloy exhibits a reactivity smaller than that of pure Sn or Pt(111).

It may be argued that the low reactivity of the alloy with respect to tin is due to the fact that the bimetallic system does not have adsorption sites with two or three adjacent tin atoms ("ensemble effects" [31,32]). But the differences in reactivity between $\operatorname{Pt}(111)$ and $(\sqrt{3} \times \sqrt{3}) \mathrm{R} 30^{\circ}-\mathrm{Sn} / \mathrm{Pt}(111)$ can only be explained invoking "electronic effects", since in the surface alloy there are plenty of 


\section{$(\sqrt{3} \mathrm{x} \sqrt{3}) \mathrm{R} 30^{\circ}-\mathrm{Sn} / \operatorname{Pt}(111) \quad \theta_{\mathrm{Sn}}=0.33 \mathrm{ML}$}
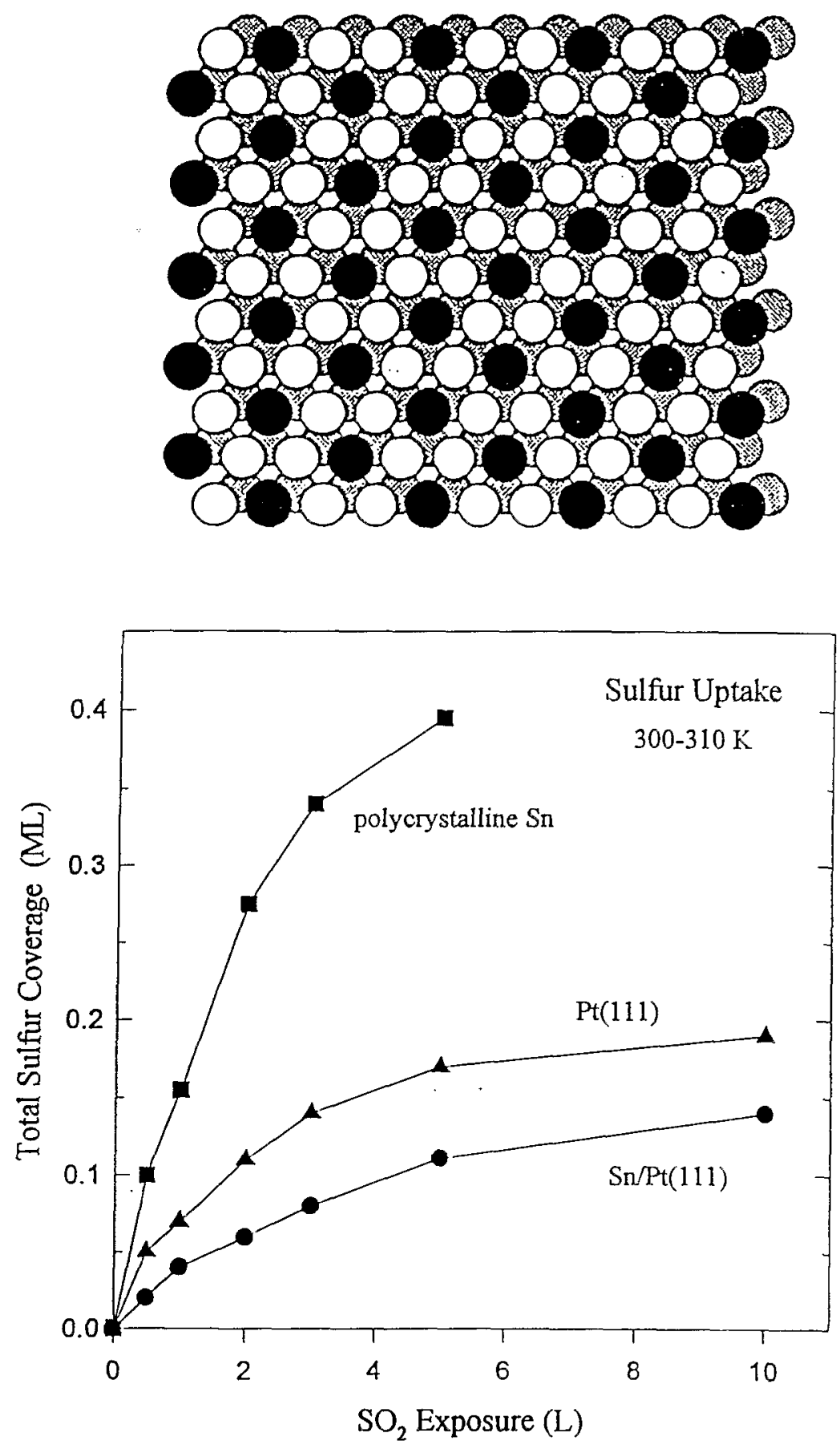

Fig 21 Top: Structural geometry for a $(\sqrt{3} \times \sqrt{3}) \mathrm{R} 30^{\circ}-\operatorname{Sn} / \operatorname{Pt}(111)$ surface alloy. The dark and white circles represent Sn and Pt atoms, respectively. The Sn atoms are present only in the top layer. Bottom: Total sulphur uptake $\left(\mathrm{SO}_{\mathrm{x}}+\mathrm{S}\right)$ for the adsorption of $\mathrm{SO}_{2}$ on polycrystalline $\mathrm{Sn}$, $\mathrm{Pt}(111)$, and $\mathrm{a}(\sqrt{3} \times \sqrt{3}) \mathrm{R} 30^{\circ}-\mathrm{Sn} / \mathrm{Pt}(111)$ alloy. Reprinted from ref. [27]. 
adsorption sites with two or three adjacent $\mathrm{Pt}$ atoms and some $\mathrm{Pt}$ atoms are being replaced with $\mathrm{Sn}$ atoms which, in principle, should be more reactive. The importance of "electronic effects" has been confirmed by theoretical calculations [27,29]. Ab initio SCF calculations indicate that the $\mathrm{Pt}$ atoms in $(\sqrt{3} \times \sqrt{3}) \mathrm{R} 30^{\circ}$ $\mathrm{Sn} / \mathrm{Pt}(111)$ interact poorly with the LUMO of $\mathrm{SO}_{2}$, leading to a small adsorption energy and hindering the dissociation of S-O bonds [27]. Density-functional slab calculations for the adsorption of atomic sulphur on a $\mathrm{p}(2 \times 2)-\mathrm{Sn} / \mathrm{Pt}(111)$ surface give adsorption energies on the pure $\mathrm{Pt}$ hollow sites that are $7-9 \mathrm{kcal} / \mathrm{mol}$ smaller than on $\operatorname{Pt}(111)$ [29]. Thus, "electronic effects" probably play an important role in the low chemical affinity of Sn/Pt alloys for sulphur-containing molecules $\left(\mathrm{S}_{2}, \mathrm{H}_{2} \mathrm{~S}, \mathrm{SO}_{2}\right.$, thiophene, etc) $[26-29,72]$. This does not imply that "ensemble" [32,72] or "geometrical effects" [73] are negligible. For example, in the case of thiophene on $\mathrm{p}(2 \times 2)-\mathrm{Sn} / \mathrm{Pt}(111)$ and $(\sqrt{3} \times \sqrt{3}) \mathrm{R} 30^{\circ}-\mathrm{Sn} / \mathrm{Pt}(111)$, one is dealing with a bulky adsorbate and small ensembles of Pt atoms [32,72] or geometrical blocking of $\mathrm{Pt}-$ adsorbate interactions by tin [72,73] help to prevent the decomposition of the sulphur-containing molecule.

$\mathrm{Cu}, \mathrm{Ag}$ and $\mathrm{Sn}$ are added to $\mathrm{Pt}$ catalysts as site blockers to improve their selectivity for the reforming of hydrocarbons $[4,31,33,64-66]$. In this respect the effects of the admetals are more or less similar. From the trends discussed above, it is clear that tin is a much better choice than $\mathrm{Cu}$ or $\mathrm{Ag}$ when trying to minimize the sensitivity of $\mathrm{Pt}$ reforming catalysts toward sulphur poisoning.

Palladium has a high catalytic activity for the selective hydrogenation of olefins, the oxidation of alcohols, cyclotrimerization of acetylene, and the removal of $\mathrm{CO}$ and NO from automobile exhaust gases [3-5,7]. One of the major limitations in the use of Pd in industrial catalysis is its extreme sensitive to sulphur poisoning [6,74]. Experimental and theoretical studies indicate that bimetallic bonding can reduce the reactivity of palladium toward sulphurcontaining molecules [28,72,75-77]. The interaction of $\mathrm{SO}_{2}$ with $\mathrm{Pd}$ in bimetallic systems has been studied in detail using a combination of photoemission and theoretical ( $a b$ initio SCF, density functional) calculations $[28,72,77]$. On pure palladium surfaces, $\mathrm{SO}_{2}$ adsorbs molecularly at $100 \mathrm{~K}$ and dissociates (60-70\%) at temperatures between 200 and $400 \mathrm{~K}$ leaving large coverages $(>0.5 \mathrm{ML})$ of $\mathrm{S}$ and $\mathrm{O}$ on the surface [28]. A very different behaviour is found for the adsorption of $\mathrm{SO}_{2}$ on a palladium monolayer supported on $\mathrm{Rh}(111)$ [28]. At $100 \mathrm{~K}, \mathrm{SO}_{2}$ chemisorbs molecularly on a $\mathrm{Pd}_{1.0} / \mathrm{Rh}(111)$ surface and heating to $300 \mathrm{~K}$ produces the desorption of almost $80 \%$ of the adsorbed $\mathrm{SO}_{2}$, leaving a few $\mathrm{S}$ adatoms and no $\mathrm{SO}_{\mathrm{x}}$ species on the surface. In this respect, the $\mathrm{Pd}_{1.0} / \mathrm{Rh}(111)$ system is less chemically active than polycrystalline $\mathrm{Pd}, \mathrm{Pd}(100)$, or $\mathrm{Rh}(111)$ [28]. The results of theoretical studies clearly indicate that bimetallic bonding weakens the $\mathrm{Pd} \leftrightarrow \mathrm{SO}_{2}$ bonding interactions $[28,77]$. In the bond between $\mathrm{SO}_{2}$ and palladium, a transfer of electrons from the metal into the LUMO of $\mathrm{SO}_{2}$ (see Figure 22) plays a dominant role in the bonding energy of the molecule 


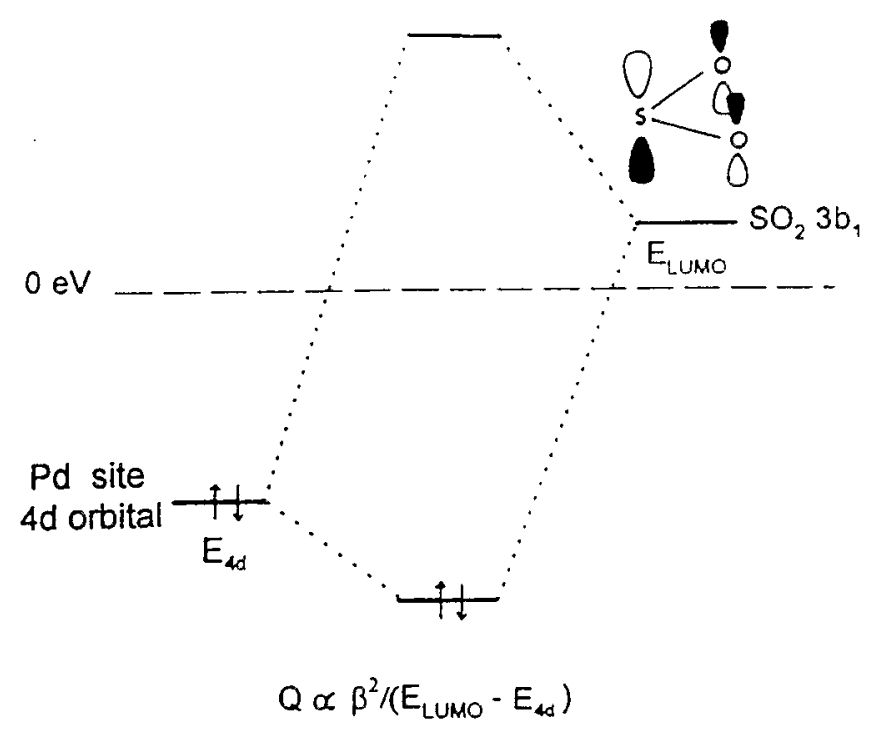

Fig 22 Bonding interactions between the LUMO of $\mathrm{SO}_{2}$ and an occupied Pd $4 \mathrm{~d}$ orbital. Reprinted from ref. [28].

$[77,78]$. This $\pi$ back donation leads to a weakening of the S-O bonds, since the LUMO of $\mathrm{SO}_{2}$ is $\mathrm{S}-\mathrm{O}$ antibonding. On the $\mathrm{Pd}_{1.0} / \mathrm{Rh}(111)$ surface, the $\mathrm{Pd} \leftrightarrow \mathrm{Rh}$ interactions reduce the electron donor ability of palladium producing weaker $\mathrm{Pd}$ $\mathrm{SO}_{2}$ bonds and stronger $\mathrm{S}-\mathrm{O}$ bonds than on $\mathrm{Pd}(111)[28,77]$. Even much weaker adsorption bonds are found when $\mathrm{Pd}$ is supported on surfaces of s,p or early transition metals $[28,72,77]$. For example, in $\mathrm{Pd}_{1.0} / \mathrm{Mo}(110)$ and $\mathrm{Pd}_{1.0} / \mathrm{Al}(111)$, bimetallic bonding largely shifts the Pd $4 \mathrm{~d}$ band toward higher binding energy [48] preventing effective interactions with the $\mathrm{LUMO}$ of $\mathrm{SO}_{2}$ (i.e. very large $\mathrm{E}_{4 \mathrm{~d}}$ to $\mathrm{E}_{\mathrm{LUMO}}$ separations in the diagram of Figure 22) [77]. A similar principle is useful for reducing the rate of thiophene dissociation on $\mathrm{Pd} / \mathrm{Mo}(110)[72,78]$. When following this approach one has to find a good balance between the decrease in the overall catalytic activity of $\mathrm{Pd}$ and its affinity for sulphur [77]. Such a balance has been observed in the case of $\mathrm{Pd} / \mathrm{Rh}, \mathrm{Pd} / \mathrm{Mn}$ and $\mathrm{Pd} / \mathrm{Ni}$ catalysts $[75,76,79]$. All these results together indicate that bimetallic bonding is a viable route for increasing the sulphur tolerance of metal catalysts.

\section{Conclusion}

In recent years, several new interesting phenomena have been discovered when studying the interaction of sulphur with bimetallic surfaces using the modern techniques of surface science. Very small amounts of sulphur can induce dramatic changes in the morphology of bimetallic surfaces. The 
electronic perturbations associated with the formation of a heteronuclear metalmetal bond affect the reactivity of the bonded metals toward sulphur. This can be a very important issue to consider when trying to minimize the negative effects of sulphur poisoning or dealing with the design of desulfurization catalysts.

\section{ACKNOWLEDGEMENT}

Many of the studies described above were done in collaboration with $\mathrm{M}$. Kuhn, S. Chaturvedi, T. Jirsak, S.Y. Li, J. Dvorak and R.Q. Hwang. Special thanks to all of them for their superb contributions. This work was carried out at Brookhaven National Laboratory under Contract NO. DE-ACO2-98CH10886 with the US Department of Energy (Division of Chemical Sciences).

\section{REFERENCES}

[1] J.G. Speight, The Chemistry and Technology of Petroleum, $2^{\text {nd }}$ ed, Dekker, New York, 1991.

[2] A.C. Stern, R.W. Boubel, D.B. Turner, and D.L. Fox, Fundamentals of Air Pollution, $2^{\text {nd }}$ ed, Academic Press, Orlando, 1984.

[3] K.C. Taylor, Catal. Rev. Sci. Eng. 35 (1993) 457.

[4] J.M. Thomas and W.J. Thomas, Principles and Practice of Heterogeneous Catalysis, $\mathrm{VCH}$, New York, 1997.

[5] B.C. Gates, Catalytic Chemistry, Wiley, New York, 1992.

[6] C.H. Bartholomew, P.K Agrawal and J.R. Katzer, Adv. Catal. 31 (1982) 135.

[7] G. Ertl, H. Knözinger, and J. Weitkamp (eds.), Handbook of Heterogeneous Catalysis, Wiley-VCH, New York, 1997.

[8] R.R. Chianelli, M. Daage, and M.J. Ledoux, Adv. Catal. 40 (1994) 177.

[9] C.C. Knight and G.A. Somorjai, Surf. Sci. 240 (1990) 101.

[10] D.A. Chen, C.M. Friend, and H. Xu, Langmuir 12 (1996) 1528.

[11] M. Kuhn and J.A. Rodriguez, Chem. Phys. Lett. 231 (1994) 199.

[12] M. Kuhn, J.A. Rodriguez and J. Hrbek, Surf. Sci. 314 (1994) L897.

[13] M. Kuhn and J.A. Rodriguez, J. Phys. Chem. 98 (1994) 12059.

[14] J.C. Dunphy, C. Chapelier, D.F. Ogletree and M.B. Salmeron, J. Vac. Sci. Technol. B, 12 (1994) 1742.

[15] M. Kuhn and J.A. Rodriguez, Catal. Lett. 32 (1995) 345.

[16] J.A. Rodriguez and M. Kuhn, J. Phys. Chem. 99 (1995) 9567.

[17] M. Kuhn and J.A. Rodriguez, J. Catal. 154 (1995) 355.

[18] F.H. Ribeiro, A.L. Bonivardi, C. Kim and G.A. Somorjai, J. Catal. 150 (1994) 186.

[19] M. Kuhn and J.A. Rodriguez, Surf. Sci. 355 (1996) 85.

[20] M. Kuhn and J.A. Rodriguez, Surf. Sci. 336 (1995) 1.

[21] W.K. Kuhn, J.-H. He, and D.W. Goodman, J. Vac. Sci. Technol. A, 10 (1992) 2477.

[22] J.A. Rodriguez, M. Kuhn and J. Hrbek, J. Phys. Chem. 100 (1996) 3799.

[23] J. Hrbek, J. de la Figuera, K. Pohl, T. Jirsak, J.A. Rodriguez, A.K. Schmid, N.C. Bartelt, and R.Q. Hwang, J. Phys. Chem. B, 103 (1999) 10557.

[24] K. Pohl, M.C. Bartelt, J. de la Figuera, N.C. Bartelt, J. Hrbek, and R.Q. Hwang, Nature, 397 (1999) 238. 
[25] J.A. Rodriguez and M. Kuhn, J. Vac. Sci. Technol. A, 15 (1997) 1608.

[26] J.A. Rodriguez, S. Chaturvedi, T. Jirsak, and J. Hrbek, J. Chem. Phys. 109 (1998) 4052.

[27] J.A. Rodriguez, T. Jirsak, S. Chaturvedi, and J. Hrbek, J. Am. Chem. Soc. 120 (1998) 11149.

[28] J.A. Rodriguez, T. Jirsak and S. Chaturvedi, J. Chem. Phys. 110 (1999) 3138.

[29] J.A. Rodriguez, J. Hrbek, M. Kuhn, T. Jirsak, S. Chaturvedi and A. Maiti, J. Chem. Phys. 113 (2000) 11284.

[30] J.A. Rodriguez and J. Hrbek, Accounts of Chem. Research, 32 (1999) 719.

[31] J.H. Sinfelt, Bimetallic Catalysts, Wiley, New York, 1983.

[32] W.H.M. Sachtler, Faraday Disc. Chem. Soc. 72 (1981) 7.

[33] V. Ponec, Adv. Catal. 32 (1983) 149.

[34] J.A. Rodriguez and D.W. Goodman, Surf. Sci. Reports 14 (1991) 1.

[35] S. Galvagno et al, J. Catal. 69 (1981) 283; 61 (1980) 223.

[36] J.W. Niemantsverdriet, P. Dolle, K. Markert and K. Wandelt, J. Vacuum Sci. Technol. A, 5 (1987) 875.

[37] S.R. Kelemen and T.E. Fisher, Surf. Sci. 87 (1979) 53.

[38] J.A. Rodriguez, J. Dvorak, T. Jirsak and J. Hrbek, Surf. Sci. 490 (2001) 315.

[39] J. Hrbek, J. de la Figuera, K. Pohl, A.K. Schmid, N.C. Bartelt and R.Q. Hwang, to be published.

[40] R.Q. Hwang, J. Schroder, C. Gunther and R.J. Behm, Phys. Rev. Lett. 67 (1991) 3279.

[41] J.A. Rodriguez, M. Kuhn and J. Hrbek, J. Phys. Chem. 100 (1996) 15494.

[42] Lange's Handbook of Chemistry, $13^{\text {th }}$ ed, McGraw-Hill, New York, 1985

[43] J.A. Rodriguez, J. Dvorak and T. Jirsak, Surf. Sci. 457 (2000) LA13.

[44] K. Pohl, J. de la Figuera, M.C. Bartelt, N.C. Bartelt, J. Hrbek and R.Q. Hwang, Surf. Sci. 433-435 (1999) 506.

[45] J. Hrbek, M. Kuhn and J.A. Rodriguez, Surf. Sci. 356 (1996) L423.

[46] G.O. Potshke and R.J. Behm, Phys. Rev. B, 44 (1991) 1442.

[47] C. Gunther, J. Vrijmoeth, R.Q. Hwang, and R.J. Behm, Phys. Rev. Lett. 74 (1995) 754.

[48] J.A. Rodriguez, Surf. Sci. Reports, 24 (1996) 223.

[49] R. Wu and A.J. Freeman, Phys. Rev. B, 52 (1995) 12419.

[50] P.J. Feibelman, Surf. Sci. 313 (1994) L801.

[51] L.Z. Mezey and J. Giber, Jpn. J. Appl. Phys. 21 (1982) 1569.

[52] C. Kittel, Introduction to Solid State Physics, $6^{\text {th }}$ ed, Wiley, New York, 1986.

[53] J.A. Rodriguez and M. Kuhn, J. Phys. Chem. 98 (1994) 11251.

[54] J.A. Rodriguez and M. Kuhn, J. Chem. Phys. 102 (1995) 4279.

[55] R.E. Watson and L.H. Bennett, Phys. Rev. B, 15 (1977) 5136.

[56] J.A. Rodriguez and M. Kuhn, Chem. Phys. Lett. 240 (1995) 435.

[57] J.A. Rodriguez, S.Y. Li, J. Hrbek, H.H. Huang and G.-Q. Xu, J. Phys. Chem. 100 (1996) 14476.

[58] J.A. Rodriguez, S.Y. Li, J. Hrbek, H.H. Huang and G.-Q. Xu, Surf. Sci. 370 (1997) 85.

[59] S. Harris and R.R. Chianelli, J. Catal. 98 (1986) 17.

[60] R.R. Chianelli, T.A. Pecoraro, T.R. Halbert, W.-H. Pan, and E.I. Stiefel, J. Catal. 86 (1984) 226.

[61] J.A. Rodriguez, Polyhedron, 16 (1997) 3177.

[62] S.Y. Li, J.A. Rodriguez, J. Hrbek, H.H. Huang, and G.Q. Xu, Surf. Sci. 366 (1996) 29. 
[63] J.A. Rodriguez, J. Dvorak, T. Jirsak, S.Y. Li, J. Hrbek, A.T. Capitano, A.M. Gabelnick, and J.L. Gland, J. Phys. Chem. B, 103 (1999) 8310.

[64] C. Xu, J.W. Peck and B.E. Koel, J. Am. Chem. Soc. 115 (1993) 751.

[65] O.A. Barias, A. Holmen, and E.A. Blekkan, J. Catal. 158 (1996) 1.

[66] J. Szanyi and M.T. Paffett, J. Am. Chem. Soc. 117 (1995) 1034.

[67] S. Pick, Surf. Sci. 436 (1999) 220.

[68] Y. Jeon, J. Chen, and M. Croft, Phys. Rev. B, 50 (1994) 6555.

[69] P. Ross, J. Vac. Sci. Technol. A, 10 (1992) 2546.

[70] S.H. Overbury, D.R. Mullins, M.T. Paffett and B.E. Koel, Surf. Sci. 254 (1991) 45.

[71] S.H. Overbury and Y.-S. Ku, Phys. Rev. B, 46 (1992) 7868.

[72] J.A. Rodriguez, J. Dvorak and T. Jirsak, to be published.

[73] C. Xu and B.E. Koel, Surf. Sci. 327 (1995) 38.

[74] J.A. Rodriguez, S. Chaturvedi and T. Jirsak, Chem. Phys. Lett. 296 (1998) 421.

[75] P.C. L'Argentiere, M.M. Cañon, N.S. Figoli and J. Ferron, Appl. Surf. Sci. 68 (1993) 41.

[76] P.C. L'Argentiere, M.M. Cañon and N.S. Figoli, Appl. Surf. Sci. 89 (1995) 63.

[77] J.A. Rodriguez and L. Gonzalez, to be published.

[78] H. Sellers and E. Shustorovich, Surf. Sci. 346 (1996) 322.

[79] D.M. DiCicco, A.A. Adamczyk, and K.S. Patel, Book of Abstracts for the $210^{\text {th }}$ American Chemical Society National Meeting (Chicago, August 1995), Fuel-145. 